\title{
The Interpolation Evolution Method for damage localization in structures under seismic excitation
}

\author{
C. Iacovino ${ }^{1}$, R. Ditommaso ${ }^{1}$, F.C. Ponzo ${ }^{1,}$ M.P. Limongelli ${ }^{2}$ \\ ${ }^{1}$ University of Basilicata, School of Engineering, Potenza, Italy \\ ${ }^{2}$ Department of Architecture, Built Environment and Construction Engineering, Milano, Italy
}

\begin{abstract}
SUMMARY
In the aftermath of an earthquake, data acquired by a monitoring system can be used to identify possible damage that occurred in the structure by using algorithms to estimate proper damage features. In this paper, a new method is proposed for damage localization in beam-like structures under seismic excitation. The proposed algorithm, named the Interpolation Evolution Method (IEM), is based on the combination of two existing methods: the Interpolation Method (IM) and the Curvature Evolution Method (CEM). Only responses recorded in terms of storey accelerations are required to estimate the damage feature with the combined IEM approach. This method does not require a priori knowledge of a 'signature' of the structure since it exploits responses recorded during a single strong motion event. Herein, the IEM is applied to case studies of two reinforced concrete frames excited by several different ground motions, simulated using nonlinear finite element (FE) models and recorded during experimental tests carried out on a shaking table at the University of California, San Diego (USA)[SE1] and at the University of Basilicata (Italy).
\end{abstract}

KEY WORDS: Structural Health Monitoring; Damage Localization; Curvature Evolution Method, Interpolation Method.

\section{INTRODUCTION}

Over the last few years, structural health monitoring has received growing interest from professionals and the research community in a wide spectrum of applications across different fields of engineering, as evidenced by the large number of monitoring systems installed in countries around the world.

In seismic regions, these systems allow an objective estimation of the structural damage after a strong motion earthquake. Vibration-based damage identification techniques have been widely applied for the assessment of the health of the buildings.

These methods make use of changes in dynamic characteristics (such as eigenfrequencies, equivalent viscous damping factors and modal or operational shapes) over time in order to identify structural damage. Experimental modal analysis (EMA) has been used as a tool for identifying the dynamic parameters of a structure based on lowamplitude vibration data. It should be emphasized that the success of damage identification based on EMA depends strongly on the accuracy and completeness of the identified structural dynamic properties [1]-[3].

Researchers have worked to set up new methodologies for SHM based on the detection of variations in the structural dynamic characteristics, namely, the modal parameters (frequencies, modal shapes[SE2], damping) or non-modal parameters such as the operational deflection shapes (ODS) after a strong seismic event [4]-[11].

Many of the methods proposed in the literature carry out damage identification through a comparison of the values of a damage feature (for example, the first modal frequency) in the original (undamaged) state and in the (possibly damaged) current state. The different ways to perform this comparison have led to a number of different approaches [1], [3], [12]-[24]. For damage detection purposes (identification of the existence of damage), frequencies can be reliably used as damage feature [25]-[27], but the effect of environmental changes has to be properly taken into account either by removing its effect on the responses or quantifying the influence in order to define a lower boundary of damage detectability [28]-[33]. In contrast, damage localization frequencies are hardly able to give reliable information. To date, the application of frequency changes to damage localization is limited to very simple specimens tested in a controlled laboratory environment and does not include real structures. The variations in the frequencies during earthquakes depends on the intensity of the shaking and on the damage, so if the intensity of the earthquake and/or the damage are low, the effect on the frequencies may be lower than 5\%. In these cases, the variations in the frequencies are not reliable indicators of damage because the variations in frequencies of this magnitude may be easily induced by environmental sources such as temperature or humidity. 
There are more effective methods to localize damage, based on the analysis of changes in the modal or operational shapes and/or in their derivatives such as slopes, curvatures or strain energy [16]-[40]. Modal curvatures can be very sensitive to errors introduced by the experimental process needed for their evaluation: the effect of noise in the recorded response is enhanced by the differentiation needed to compute curvature; thus, their use for damage localization purposes is hardly successful in practical applications.

To overcome the problems related to the estimation of curvature, reference [24] proposed the Interpolation Method (IM) based on a damage feature defined in terms of the loss of smoothness (that is, the local increases of curvature) of the operational shapes induced by a local reduction of stiffness. The advantage of this method is that it allows the detection of local changes in curvature (losses of stiffness) without requiring the direct estimation of curvature, thus overcoming the problems connected to differentiation of the modal or operational shapes. Recently, extension of the IM method to modal shapes has been proposed [35]. The damage feature is defined in terms of the variation in the interpolation error between a reference and a (potentially) damaged configuration. The interpolation error is computed for each configuration by interpolating with a smooth function (namely, a cubic spline for a beam-like structure); the operational (or the modal) shapes are computed from responses recorded on the structure during vibrations. The main advantage of this method is that local variations in curvature are detected without actually computing the curvature, thus avoiding all problems related to the differentiation with noisy signals. A possible drawback of the IM may be the need for two sets of responses, recorded before and after damage, for the computation of the damage feature. In this method, it is implicitly assumed that the structure behaves linearly during these vibrations, so that the operational (or modal) shapes can be computed and assumed to be 'signatures' of the structure in the different states (undamaged or damaged). This assumption may limit the use of the IM when only responses recorded during a strong seismic event, inducing a nonlinear response, are available. [SE3]The term 'signature' refers to a feature, in this case, the operational shapes, that characterize each state of the structure. To overcome the latter limitation, herein, a combination of the IM with the Curvature Evolution Method presented in reference [34] is proposed. The CEM is based on the use of a band-variable filter able to extract the nonlinear response of each mode of vibration from recorded responses. The detection of the possible changes that occurred during a single earthquake is carried out in terms of a damage feature defined in terms of the modal curvature. The latter is retrieved at different times from the responses recorded during the seismic event, and the comparison of its values at different times allows the detection of its possible variations. The approach used in the CEM, based on the band-variable filter, reduces the effect of noise, thus allowing a reliable estimate of the modal shape. Furthermore, the joint application of the CEM and the IM overcomes the problems related to the estimation of curvature because the computation of the latter is not needed.

The combination of the two methods, CEM and IM, is performed herein using the band-variable filter to extract the nonlinear response of the structure; assuming a damage feature, the variation in the interpolation error is computed at different times during the strong motion[SE4]. The combined approach, named the Interpolation Evolution Method (IEM), eliminates the drawbacks connected with the estimation of curvature in the CEM and with the need of two sets of linear responses to the vibrations (before and after damage) of the IM.

In the first part of this paper, the results retrieved from the separate application of the two methodologies are presented and compared to the results obtained from the application of the IEM for two numerical case studies. In the second part of the paper, the IEM is validated through its application to data recorded during two experimental case studies. A full-scale 7-storey reinforced concrete frame is tested on the University of California, San Diego (UCSD) shake table and a reinforced concrete frame $1 / 4$ scaled model is tested on the shaking table of the University of Basilicata. The last two case studies tested the method in 'real-world' conditions, and all the possible sources of noise, which is one of the main shortcomings for the application of damage identification algorithms, were present.

\section{METHODOLOGIES FOR DAMAGE LOCALIZATION[SE5]}

\subsection{Curvature Evolution Method (CEM)}

The Curvature Evolution Method for damage localization is based on the use of a network of sensors installed on the structure and on the use of a band-variable filter able to extract the nonlinear response of the fundamental mode of vibration.

As described by Ditommaso et al. [34], a band-variable filter [42] is used to extract the dynamic characteristics of systems that evolve over time by acting simultaneously in both the time and frequency domains. The filter is built using the properties of convolution, linearity and invertibility of the S-Transform [43]. The S-Transform is a time-frequency localization spectral method similar to the short-time Fourier transform [44] but with a Gaussian window whose width scales inversely and whose height scales linearly with the frequency.

The filter can extract only the energy content from a non-stationary and/or nonlinear signal, preserving both the amplitude and phase in the region of interest [42]. Using this kind of approach, and choosing the appropriate 
frequency subdomain, it is possible to extract the time-varying parameters of a mode of vibration from a nonlinear signal recorded on a structure undergoing damage during a seismic event.

The filtering method is based on the following steps:

- $\quad$ Computing the $S$-Transform $W(\tau, f)$ of the signal $w(t)$.

- Generating the filtering matrix $G_{m}(\tau, f)$ that, at each time $\tau$, selects the frequency subdomain of the $S$ Transform corresponding to the mode $m$.

- Calculating the convolution in the time-frequency domain, $W_{m}(\tau, f)=G_{m}(\tau, f) \cdot W(\tau, f)$, to extract the subdomain $W_{m}(\tau, f)$ of $W(\tau, f)$ corresponding to the mode $m$.

- $\quad$ Retrieving the filtered signal $w_{m}(t)$ in the time domain through the calculation of the inverse $S$-Transform of $W_{m}(\tau, f)$.

Considering one of the instrumented locations $z_{l}$, the filtered signal in the time domain can be written as [34]

$$
w_{m}\left(z_{l}, t\right)=\int_{-\infty}^{+\infty}\left\{\int_{-\infty}^{+\infty}\left[W\left(z_{l}, \tau, f\right) \cdot G_{m}\left(z_{l}, \tau, f\right)\right] d \tau\right\} \cdot e^{-i \cdot 2 \pi f t} d f
$$

At each time, whether the recorded signal is in terms of acceleration, velocity or displacement, the set of filtered signals at all the instrumented locations give the deformed shape of the structure in the frequency subdomain corresponding to mode $m$. In the previous applications of the CEM, the procedure has been applied to extract the contribution of the fundamental mode [34]. By applying the finite differences, the curvature can be written as

$$
w_{m}^{\prime \prime}\left(z_{l}, t\right)=\frac{w_{m}\left(z_{l-1}, t\right)-2 w_{m}\left(z_{l}, t\right)+w_{m}\left(z_{l+1}, t\right)}{\left(z_{l}-z_{l-1}\right)^{2}}
$$

where $w_{m}\left(z_{l}, t\right)$ is the displacement at location $z_{l}$ at time $t$ and $w^{\prime \prime}{ }_{m}\left(z_{l}, t\right)$ the related curvature. Following Cao et al. [46], it is possible to localize the damage by analysing the singularity on the curvature of the fundamental mode shape.

In the CEM, in order to identify the damage and to localize its position, the curvature differences among adjacent storeys is assumed to be a damage feature:

$$
\Delta w_{m}^{\prime \prime}\left(z_{l}, t\right)=w_{m}^{\prime \prime}\left(z_{l}, t\right)-w_{m}{ }_{m}\left(z_{l-1}, t\right)
$$

where $w^{\prime \prime}{ }_{m}\left(z_{l}, t\right)$ is the curvature evaluated at time $t$ and location $z_{l}$ and $w^{\prime \prime}{ }_{m}\left(z_{l-1}, t\right)$ is the curvature evaluated at the same time $t$ and at a nearby location $z_{l-1}$.

The variation in the damage feature between two times is the damage index Curvature Evolution Index (CEI) defined at location $z_{1}$ and time $t$ as

$$
C E I\left(z_{l}, t\right)=\Delta w_{m}^{\prime \prime}\left(z_{l}, t\right)-\Delta w_{m}^{\prime \prime}\left(z_{l}, t_{r e f}\right)
$$

where $t_{\text {ref }}$ is a time that is assumed to be a reference to compute the possible changes (damages) of the structure.

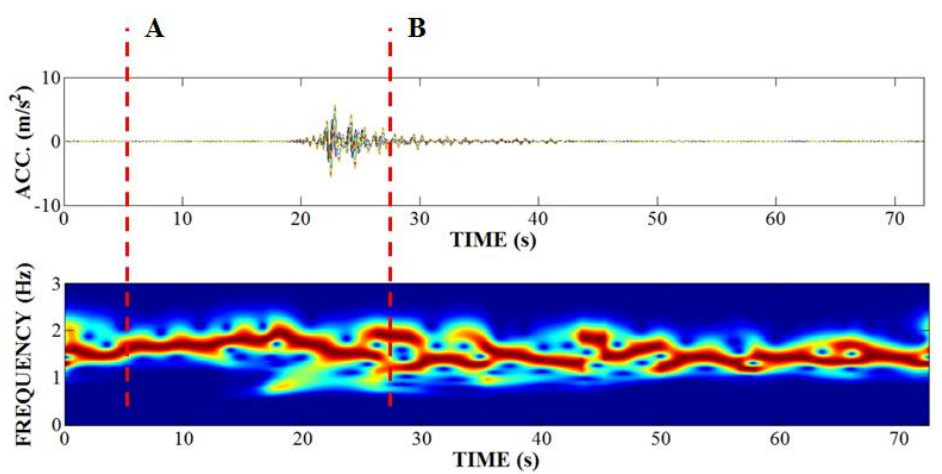

Figure 1. General evaluation of the normalized S-Transform and selection of the instants of interest: A (reference time, $t_{\mathrm{ref}}$ ) and B (minimum fundamental frequency time).

Figure 1 shows an example of the variation in the frequency of the fundamental mode extracted by means of the band-variable filter. The dotted lines indicate the time at which the mode shapes have been computed: the (A) 
reference time, which is the instant immediately before the earthquake, and (B) time corresponding to the achievement of the minimum value of the fundamental frequency. To verify the capability of the proposed approach to correctly extract the mode shape from the signal recorded on the structure (in this case, represented by a nonlinear numerical model implemented in SAP2000[SE6] [[47]]), a comparison between mode shapes retrieved from signals and mode shapes directly provided by SAP2000 is proposed in Figure 2.

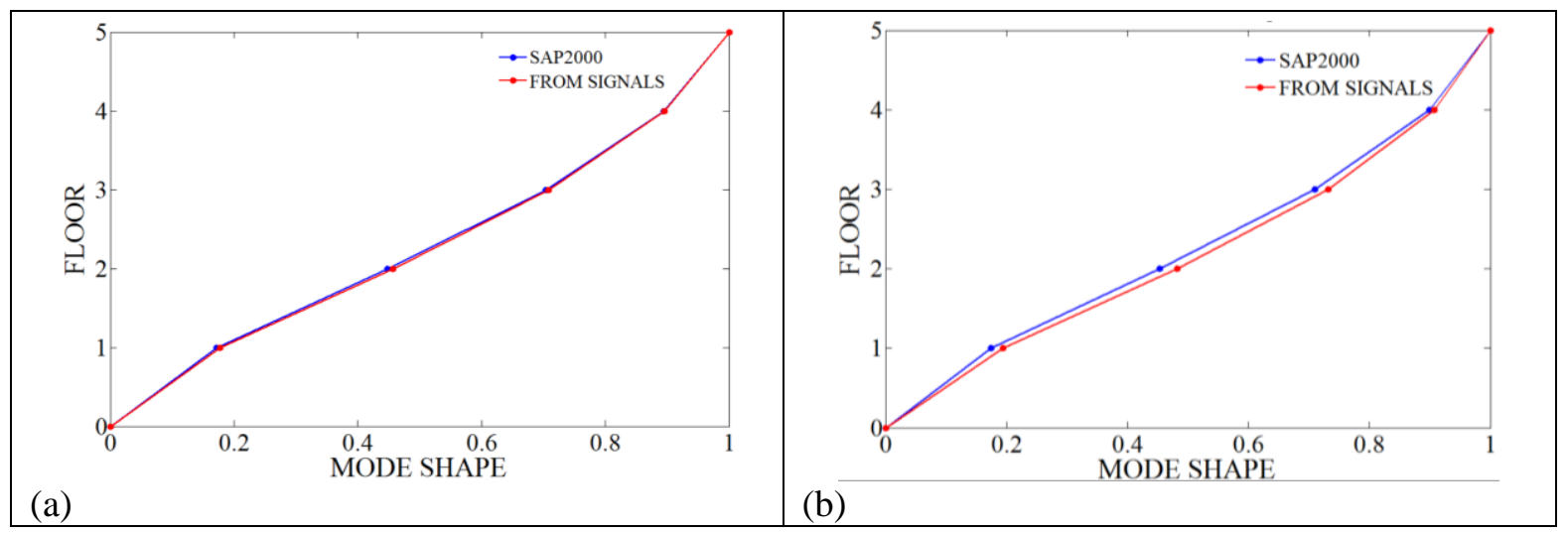

Figure 2. Comparison of mode shapes evaluated at the (a) reference time immediately before the earthquake and (b) time corresponding to the achievement of the minimum value of the fundamental frequency.

Despite the selected noisy signal, the band-variable filter provides stable results, as demonstrated in Figure 2, where a good agreement is observed between the mode shapes evaluated in stationary conditions (before the earthquake) and in non-stationary and nonlinear conditions (during the earthquake) [48] with the mode shapes provided by SAP2000.

To fully automate the procedure for damage localization, several studies are being carried out. Particularly, it is possible to automate the filtering matrix selection by using the STIRF procedure [49].

Herein, the CEM and its extension in the IEM have been applied by extracting the nonlinear response of the sole first mode from the recorded responses. The extension to the use of more than one mode could be interesting and will be the focus of further research efforts. However, it must be noted that for multi-storey regular buildings under seismic excitation, the first mode gives a far higher contribution to the response with respect to the highest modes; therefore, the contribution of the latter for the case studies reported herein can be neglected.

\subsection{Interpolation Method (IM)}

In this section, a short description of the Interpolation Method is reported. The interested reader can refer to reference [41] for further details. The procedure is based on the observation that the comparison of the operational shapes related to the undamaged and damaged phases points out a sharp reduction of smoothness of the deformed shape at the damaged story. The main idea behind the Interpolation Method is that by using a smooth function (a cubic spline) to interpolate a mode shape, the interpolation error is higher where there is an irregularity. In the case of a regular structure, the interpolation error is low at every location; in the case of an irregular structure, the interpolation error is high at the location of the irregularity and low at all other locations. A reduction of stiffness causes an increase in curvature (that is, an increase in the irregularity of the shape) and therefore an increase in the interpolation error. The damage feature is thus defined as the variation in the error related to the use of a (smooth) cubic spline function in interpolating the operational or the modal shapes of the structure. In each configuration of the structure (both in the reference and in the inspection configurations), the interpolation error can be computed at each location based on responses recorded in this configuration. A variation in the interpolation error between a reference and a possibly damaged configuration indicates the onset of damage.

Namely, at a given location of a structure, the interpolation accuracy can be defined as the difference between the measured displacement and the displacement calculated at that location by interpolating, through a spline function, the displacements measured at all the other locations equipped with a sensor. If the comparison of the interpolation error between two different phases (the reference phase and the inspection phase after a potentially damaging event) highlights a significant decrease in accuracy at one location, this is an indication of the existence of damage close to the location where this change is detected.

To remove the influence of the amplitude of displacements on the evaluation of the interpolation error and to remove the numerical errors related to the estimation of displacements from recorded accelerations, the interpolation error is defined at a given location $z_{l}$ in terms of the difference between the frequency response functions (FRFs) $H_{R}$ and $H_{S}$ of the recorded and interpolated responses, respectively, in terms of acceleration [38] with respect to the input acceleration. The interpolated FRF can be written as 


$$
H_{S}\left(z_{l}, f_{i}\right)=\sum_{j=0}^{3} c_{j, l}(f)\left(z_{l}-z_{l-1}\right)^{j}
$$

where the coefficients $\left(c_{0 l}, c_{1 l}, c_{2 l}\right.$, and $\left.c_{3 l}\right)$ are calculated from the values of the transfer functions $H_{R}$ 'recorded[SE7]' at all the other locations $\left(z \neq z_{l}\right)$ :

$$
c_{j, l}\left(f_{i}\right)=g\left(H_{R}\left(z_{k}, f_{i}\right)\right) \quad k \neq l
$$

The explicit expressions of the coefficient of the spline function $c_{j, l}$ in terms of the FRFs are determined by imposing continuity of the spline function and of its first and second derivative in the knots (that is, at the ends of each subinterval). More details on the spline interpolation procedure to calculate acceleration responses can be found in reference [39].

In terms of the FRFs, the interpolation error at location $z_{l}$ (in the following, the index $l$ will be dropped for clarity of notation) at the $i^{\text {th }}$ frequency value $f_{\mathrm{i}}$, is defined as the difference in the magnitudes between the recorded and interpolated frequency response functions:

$$
E\left(z_{l}, f_{i}\right)=\left|H_{R}\left(z_{l}, f_{i}\right)-H_{S}\left(z_{l}, f_{i}\right)\right|
$$

To characterize each location with a single error parameter, the norm of the error on the whole range of frequencies has been considered:

$$
E\left(z_{l}\right)=\sum_{i=n_{o}}^{n_{o}+N} \sqrt{E\left(z_{l}, f_{i}\right)^{2}}
$$

$N$ is the number of frequency lines in the Fourier transform included in the frequency range starting at line $n_{0}$, where the signal-to-noise ratio is high enough to allow a correct definition of the FRF. The value of the damage feature at each location equipped with a sensor is computed as the positive difference between the values of the interpolation error in the inspection $E_{\mathrm{i}}$ and reference $E_{0}$ phases.

$$
\operatorname{IDI}\left(z_{l}\right)=E_{i}\left(z_{l}\right)-E_{o}\left(z_{l}\right)
$$

Negative values of the damage index are discarded [24].

One of the main advantages of the Interpolation Method with respect to curvature-based methods for damage localization is reflected in the possibility of detecting variations in curvature while avoiding computation of the curvature itself [50]. This effectively allows avoiding the negative effects due to the enhancement of noise related to the double differentiation of the recorded deformed shapes.

It must be noted that in order to apply the Interpolation Method, two sets of responses are needed: one recorded in the reference configuration and one recorded during a later earthquake. Therefore, no assumptions are made regarding the reference configuration since the method requires responses recorded in that configuration. Of course, this could be a drawback if the structure was not monitored in its original configuration; thus, the 'signature' [SE8] of the damage feature in the reference configuration is not available. The focus of this paper is to overcome the drawback related to the need for information relevant to the reference configuration by assuming that the configuration corresponding to the beginning of the strong motion is the reference configuration, as will be detailed in the next section.

\section{INTERPOLATION EVOLUTION METHOD (IEM)}

The main fundamental idea of the combined IEM approach is to jointly exploit the performance of the bandvariable filter, providing the possibility to extract the selected mode shape instant-by-instant, with the stability of the Interpolation Method related to the detection of variations in curvature through the interpolation, instead of the direct computation, of curvatures. The interpolation is applied to the fundamental mode shape continuously extracted during the strong motion. The flow-chart of the procedure is described in Figure 3. 


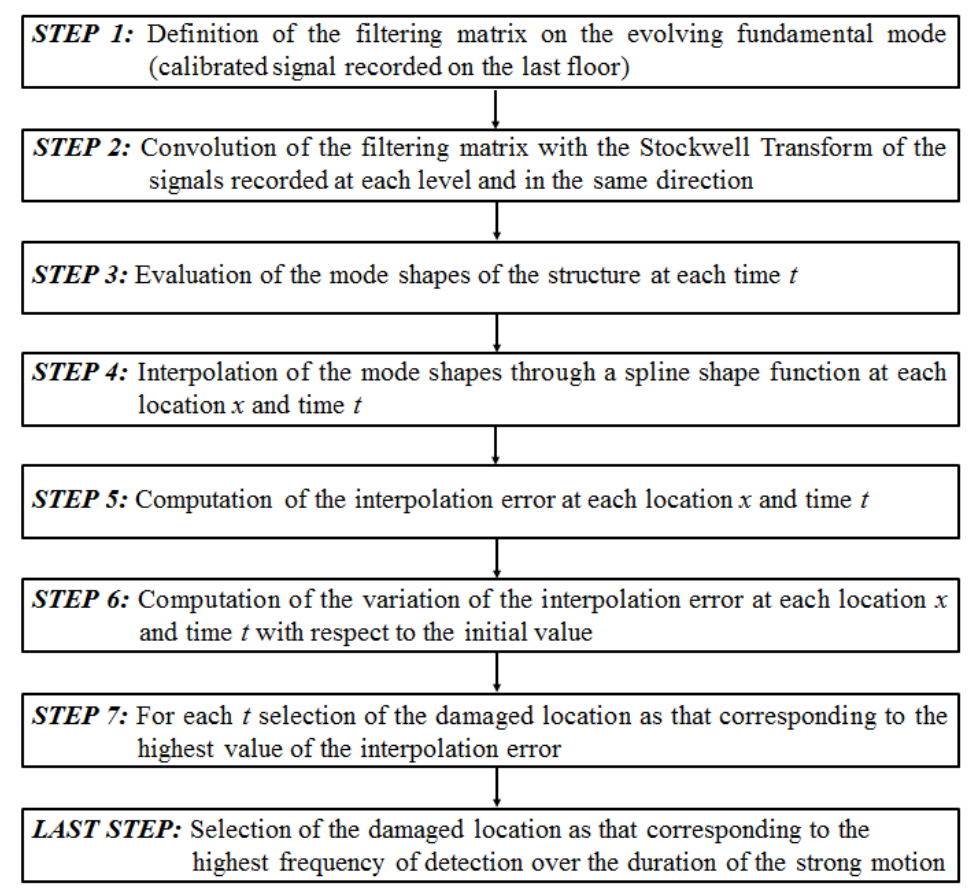

[SE9]Figure 3. Flow-chart of the IEM.

A further advantage of the proposed procedure is reflected in the possibility of computing a set of values of the damage feature to express the values of the continuous variation in the interpolation error during the earthquake. From these values, the histograms of the damage feature are computed.

In the following, the proposed method will be applied to numerical case studies (two multi-storey buildings of 5 and 8 storeys) and two experimental case studies (a slice of a multi-storey building tested on the UCSD shaking table and a reinforced concrete frame $1 / 4$ scaled model tested on the shaking table of the University of Basilicata). The numerical models have been used to test the sensitivity of the method in terms of the location and severity of damage: several scenarios with damage located at different storeys have been simulated, and nonlinear dynamic analyses have been carried out, considering the base inputs of increasing intensity. The application of the method to the real case study was meant to show the feasibility of the method to correctly locate damage in 'realworld[SE10]' conditions, where all the possible sources of damage are present. However, for the case of structures under strong seismic input, there is a quite high signal-to-noise ratio with respect to noise due to environmental or operational factors; hence, the nonlinear behaviour and the approximations related to signal processing are the main sources of noise. Therefore, the responses used for the application of the damage localization algorithm are affected by noise also for the numerical cases, even if noise has not been artificially added.

\section{NUMERICAL CASE STUDIES}

\subsection{Numerical analyses and damage scenarios}

The three methods (CEM, IM, and IEM) have been applied to the nonlinear numerical models of two reinforced concrete framed structures of respectively 5 and 8 storeys with regular geometric configurations designed for only gravity loads. The height of each story is $3 \mathrm{~m}$, and the total heights of the buildings are $15 \mathrm{~m}$ for the 5 -story building and $24 \mathrm{~m}$ for the 8 -story building (Figure 4).

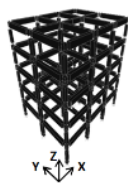

(a)

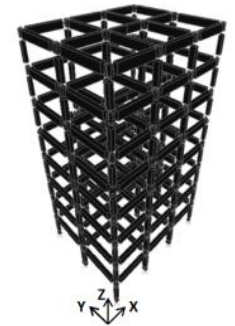

(b)

Figure 4. The numerical models are regular in plan view: (a) 5 story, (b) 8 story. 
Nonlinear dynamic analyses have been carried out using a nonlinear 3D model built in SAP2000 Nonlinear [47]. To simulate a structural nonlinear behaviour during a strong ground motion, link elements and plastic hinges were introduced at the ends of both the beam and column elements. Link elements have a pivot hysteretic behaviour, while plastic hinges have an axial load-dependent one.

The numerical analyses were performed using seven natural accelerograms, which were chosen from the Italian Accelerometric Archive (ITACA) and are compatible with the Italian Seismic Code for a soil type B [51]. The natural accelerograms were chosen with peak ground accelerations ranging between 0.1 and $0.5 \mathrm{~g}$.

Table 1. Peak ground accelerations of the seven natural accelerograms.

\begin{tabular}{|c|c|c|c|c|c|c|c|}
\hline & A1 & A2 & A3 & A4 & A5 & A6 & A7 \\
\hline PGA (g) & 0.34 & 0.34 & 0.13 & 0.15 & 0.22 & 0.48 & 0.35 \\
\hline
\end{tabular}

To identify the reference fundamental frequency before the earthquake and the final fundamental frequency after the earthquake, 20 seconds of pink noise has been added at the beginning and at the end of the accelerograms used as input. Table 2 shows the natural frequencies identified in the numerical models for the first three mode of vibration in different directions.

Table 2. Natural frequencies identified for the 5-story building and for the 8-story building.

\begin{tabular}{|c|c|c|c|c|c|c|}
\hline & $\begin{array}{c}\text { I mode } \\
\text { Translational } \mathbf{x} \\
\mathbf{f}(\mathbf{H z})\end{array}$ & $\begin{array}{c}\text { II mode } \\
\text { Translational y } \\
\mathbf{f}(\mathbf{H z})\end{array}$ & $\begin{array}{c}\text { III mode } \\
\text { Torsional } \\
\mathbf{f}(\mathbf{H z})\end{array}$ & $\begin{array}{c}\text { IV mode } \\
\text { Translational } \mathbf{x} \\
\mathbf{f}(\mathbf{H z})\end{array}$ & $\begin{array}{c}\text { V mode } \\
\text { Translational y } \\
\mathbf{f}(\mathbf{H z})\end{array}$ & $\begin{array}{c}\text { VI mode } \\
\text { Torsional } \\
\mathbf{f}(\mathbf{H z})\end{array}$ \\
\hline $\begin{array}{c}\text { 5-story } \\
\text { building }\end{array}$ & 1.187 & 1.703 & 1.710 & 3.750 & 5.262 & 5.329 \\
\hline
\end{tabular}

\begin{tabular}{|c|c|c|c|c|c|c|}
\hline & $\begin{array}{c}\text { I mode } \\
\text { Translational y } \\
\mathbf{f}(\mathbf{H z})\end{array}$ & $\begin{array}{c}\text { II mode } \\
\text { Translational } \mathbf{x} \\
\mathbf{f}(\mathbf{H z})\end{array}$ & $\begin{array}{c}\text { III mode } \\
\text { Torsional } \\
\mathbf{f}(\mathbf{H z})\end{array}$ & $\begin{array}{c}\text { IV mode } \\
\text { Translational y } \\
\mathbf{f}(\mathbf{H z})\end{array}$ & $\begin{array}{c}\text { V mode } \\
\text { Translational x } \\
\mathbf{f}(\mathbf{H z})\end{array}$ & $\begin{array}{c}\text { VI mode } \\
\text { Torsional } \\
\mathbf{f}(\mathbf{H z})\end{array}$ \\
\hline $\begin{array}{c}\text { 8-story } \\
\text { building }\end{array}$ & 0.663 & 0.797 & 0.861 & 1.99 & 2.410 & 2.582 \\
\hline
\end{tabular}

Figure 5 shows the response spectra of the seven natural accelerograms selected for the numerical simulations.

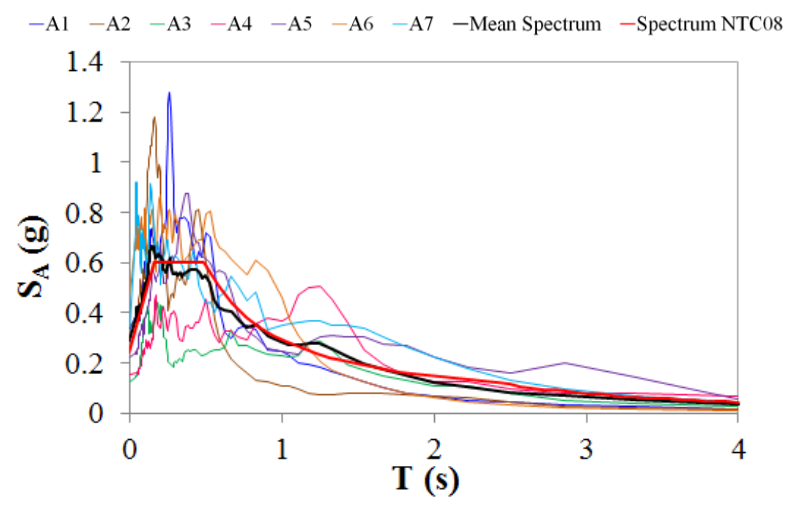

(a)

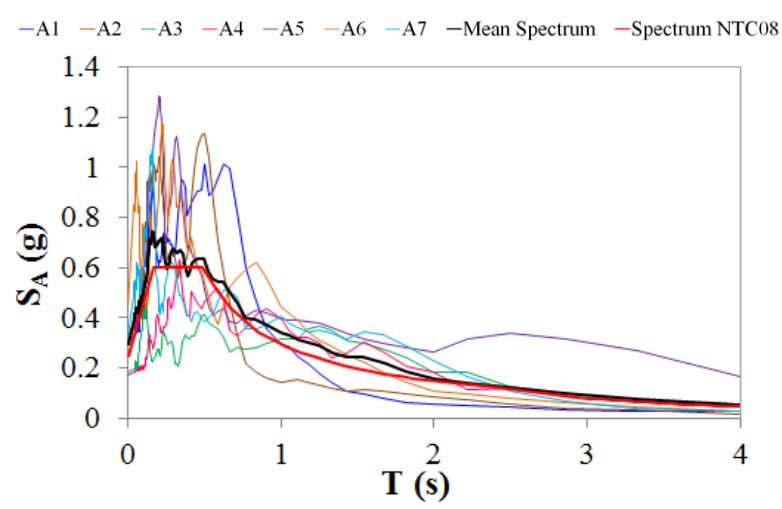

(b)

Figure 5. Response spectra of the natural accelerograms: (b) NS component; (c) WE component. 
To apply the IM, responses on the structure in the reference (undamaged) configuration are needed. These responses have been obtained by exciting the models with seven accelerograms scaled with a scaling factor equal to 0.05 .

To obtain the data needed to verify the damage localization algorithms herein, different scenarios, with damage located at different locations, were needed. To somehow 'drive' the results of the nonlinear seismic analysis, thus obtaining damage at different locations, several initial configurations of the multi-storey buildings have been considered. Specifically, the initial stiffnesses of the different storeys have been tailored in order to induce the formation of plastic hinges, that is, of damage, at different locations, specifically in the softer storeys.

The first original configuration considered for the two models denoted C5_0 and C8_0 for the $5^{\text {th }}$ and the $8^{\text {th }}$ storey buildings, respectively, is the one with a constant stiffness for all the storeys. The other configurations have been obtained by reducing the stiffness of one of the storeys by $25 \%$. The name of each configuration describes the storey where the stiffness is modified, for example, C8_4 is a configuration of the 8-storey building with a reduced stiffness of storey 4 . Under the simulated seismic excitation, damage occurred in a single storey. The responses were used to verify the capability of the proposed method to identify localized damage. In the next section, the results are discussed for a selection of both single and multiple damage scenarios.

\subsection{Discussion and results}

\subsubsection{Results of separate approaches to damage localization (CEM and IM)}

In this section, a selection of results obtained by applying each of the two methods for damage localization to the responses of the nonlinear numerical models is presented.

Figure 6 and Figure 7 show the results given by the CEM and IM for different excitations for configurations C5_0 and C8_0: the absolute value of the variation in the curvature difference $\left(\triangle \mathrm{D}_{\mathrm{CEM}}\right)$ and the variation in the interpolation error $\left(\Delta \mathrm{D}_{\mathrm{IM}}\right)$. In addition to the damage features relevant to the two methods, the values of the interstory drift have been computed for all the storeys. This information is meant to provide a reference to a widely accepted and efficient damage feature, allowing a description of the expected damage both to non-structural elements and to structural elements for different performance levels [52]. In Figure 6 and Figure 7 the peak value of the inter-storey drift between two consecutive storeys is reported (e.g., for storey 2, the inter-storey drift is reported with respect to storey 1 ).

For configuration C5_0, the simulated earthquake caused the formation of plastic hinges at the ends of all the columns between the second and third storeys, and for configuration C8_0, the simulated earthquake caused the formation of plastic hinges at the ends of all the columns between the first and second storeys. The results of the numerical analysis show that the maximum values of the drift are consistently found at the second and third storey for the 5-storey model and at the first and second storeysstoreys [SE11] for the 8-storey building.

The damage index $\Delta \mathrm{D}_{\mathrm{CEM}}$ for the CEM has been calculated in all cases considering the absolute value of the variation in the damage feature computed (according to equation (4)) at time B (when the minimum value of the fundamental frequency is reached) and at time A (reference time before the earthquake).

The damage index for the IM is computed as the positive difference $\left(\Delta \mathrm{D}_{\mathrm{IM}}\right)$ of the interpolation error retrieved from responses computed on the damaged structure and on the undamaged structure under a low intensity $\left(\mathrm{PGA}_{\mathrm{A} 1}=0.017, \mathrm{PGA}_{\mathrm{A} 5}=0.011, \mathrm{PGA}_{\mathrm{A} 6}=0.024\right.$, or $\left.\mathrm{PGA}_{\mathrm{A} 7}=0.018\right)$ seismic event; negative values of the damage features are discarded, as specified in section 2.2.

The higher values of the damage indices occur at the damaged locations for both algorithms (CEM and IM), leading to a correct localization of damage.

These results are also in agreement with the drift data.
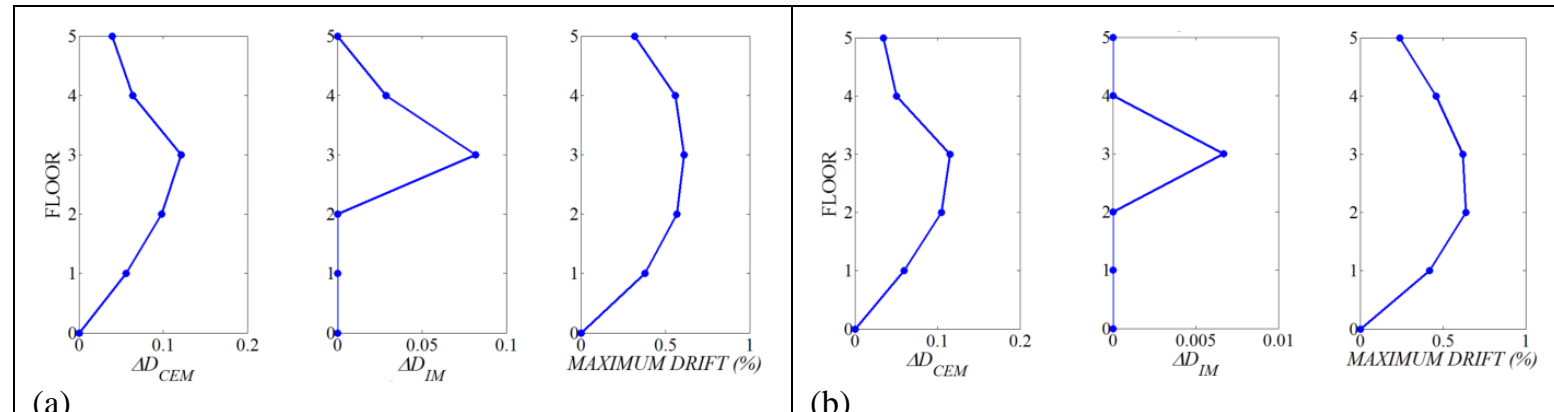

(b) 


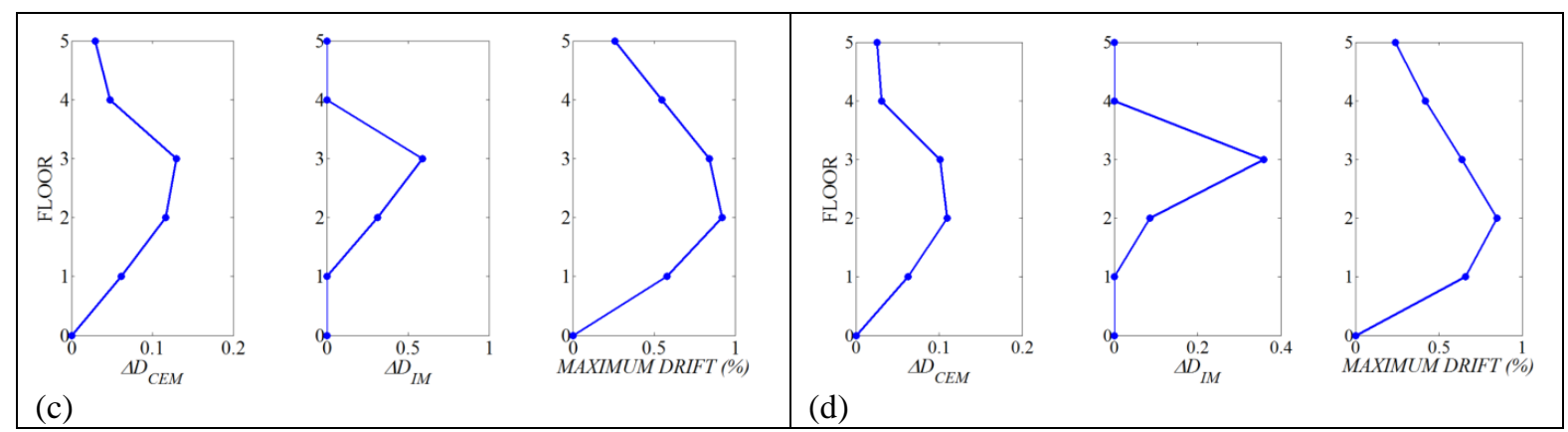

Figure 6. Configuration C5_0. Variation in the curvature difference among storeys, and variation in the interpolation error and maximum inter-story drift for the 5-story building: (a) accelerogram A1, (b) accelerogram A5, (c) accelerogram A6, (d) accelerogram A7.

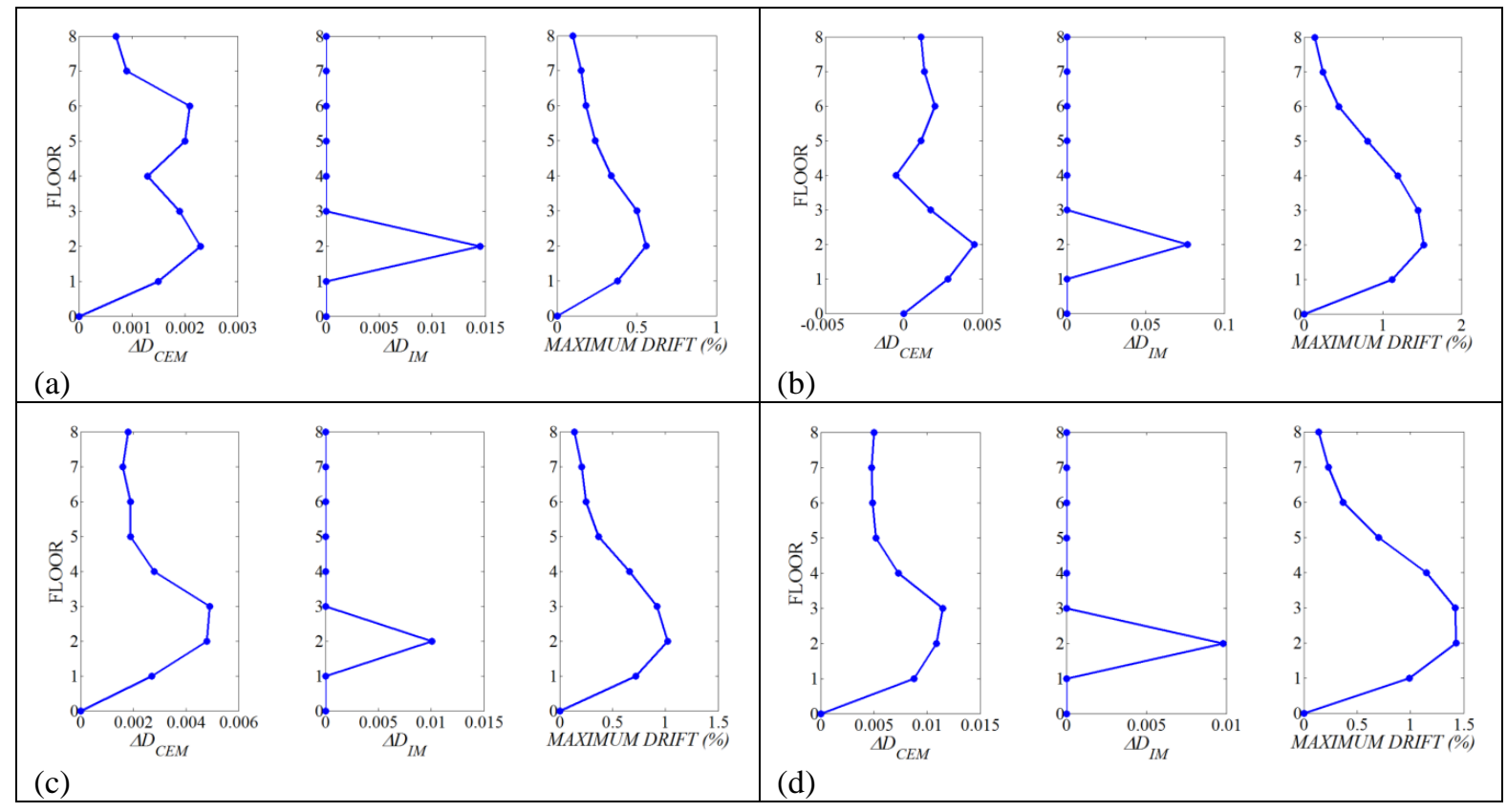

Figure 7. Configuration C8_0. Variation in the curvature difference among storeys, and variation in interpolation error and maximum inter-storey drift for the 8-story building: (a) accelerogram A1, (b) accelerogram A5, (c) accelerogram A6, (d) accelerogram A7.

\subsubsection{Results of the combined approach: the Interpolation Evolution Method}

After identifying the fundamental mode of the structure the relevant modal shape and the related variation in the interpolation error have been evaluated at each instantduring the excitation for each instrumented location.

To more clearly identify the damaged storey, Figure 8 and Figure 9 show the histograms of the identified damaged storey, that is, the number of times during the excitation that the storey is identified as the damaged one (that is, corresponding to the maximum value of the damage index) with respect to the total duration of the excitation. No probabilistic model is used herein to fit the distribution of the damage index among the storeys. The histograms reported in Figure 8 to Figure 12 point out the relative frequency of the damage detection among the storeys. For all the considered damage scenarios, the highest value of the damage feature is attained at the damaged location(s), allowing the correct localization of damage. The maximum variation in the interpolation error occurs at the second and third storey for C5_0, as determined by applying the two methodologies separately. Additionally, for configuration C8_0, the results are in agreement with those presented above. In particular, by applying the combined approach, the results are full in agreement with the inter-story drifts. 


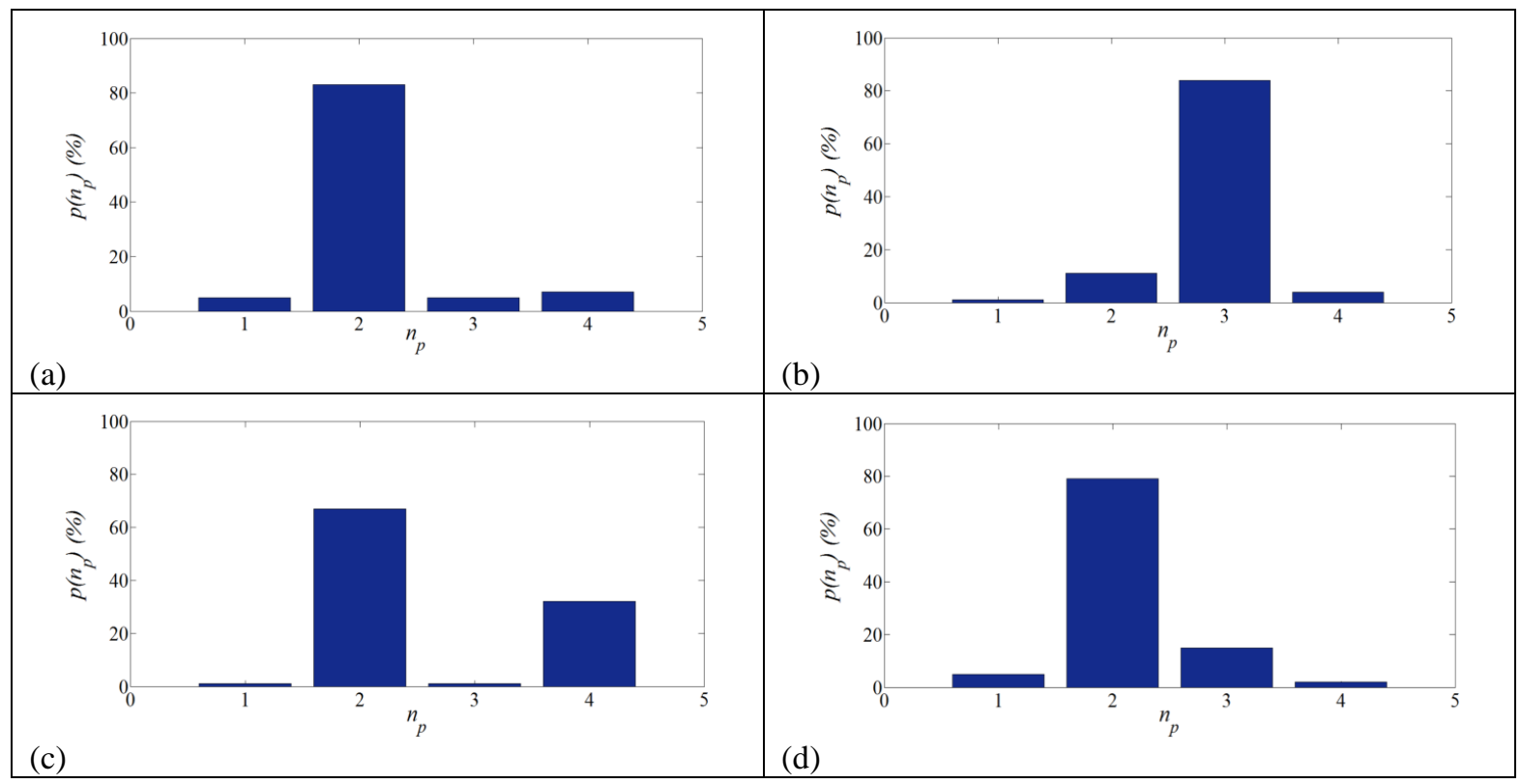

Figure 8. Configuration C5_0. Histograms of the identified damaged storey for the 5-story building: (a) accelerogram A1, (b) accelerogram A5, (c) accelerogram A6, (d) accelerogram A7.

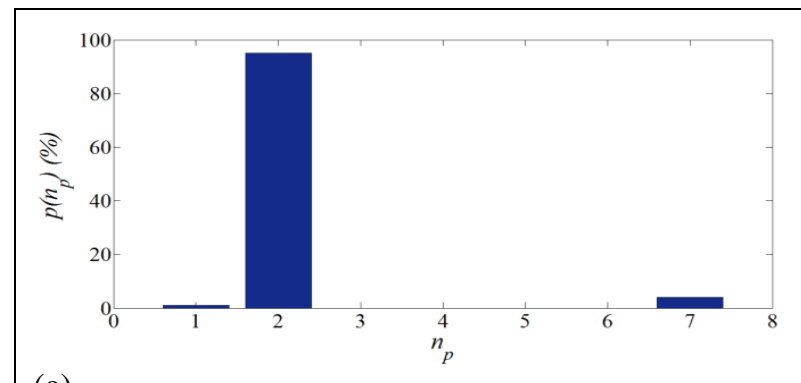

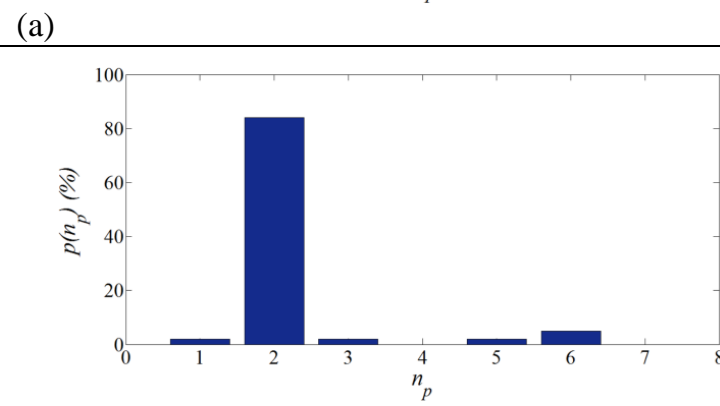

(c)

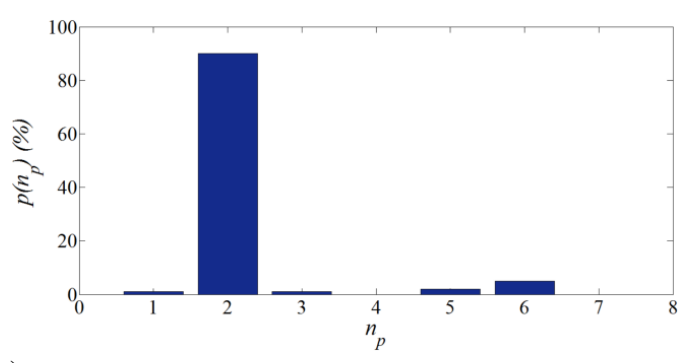

(b)

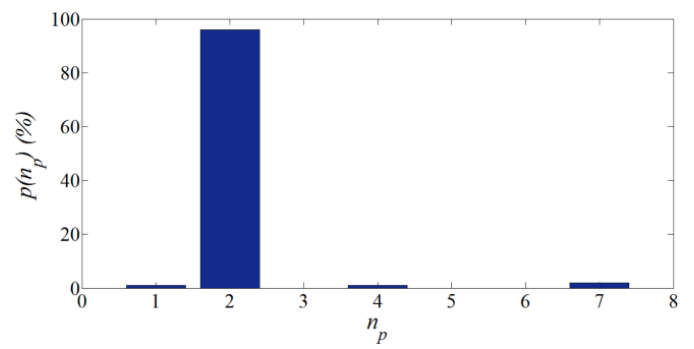

(d)

Figure 9. Configuration C8_0. Histograms of the identified damaged storey for the 8-story building: (a) accelerogram A1, (b) accelerogram A5, (c) accelerogram A6, (d) accelerogram A7.

Figure 10 and Figure 11 report the other two cases of a single damage location for the 8-storey building. For the events corresponding to the lower intensity of the shaking, some false alarms are observed, but the maximum value of the damage feature is always found at the correct damaged location. Identification is much clearer for the events with higher intensities, inducing higher stiffness reductions and therefore more severe damage. 


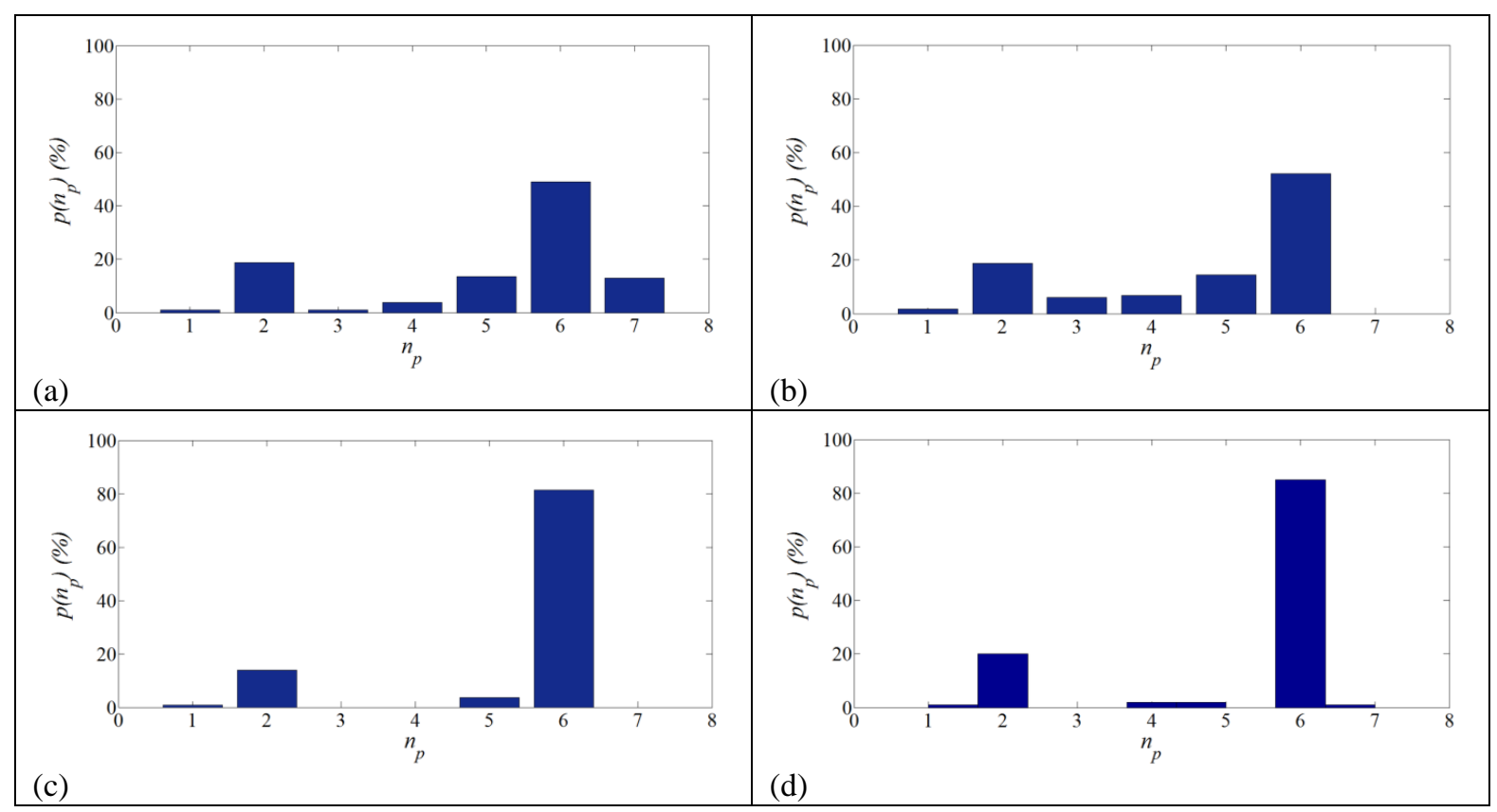

Figure 10. Configuration C8_6. Histograms of the identified damaged storey for the sixth storey of the 8-story building: (a) accelerogram A1, (b) accelerogram A5, (c) accelerogram A6, (d) accelerogram A7.

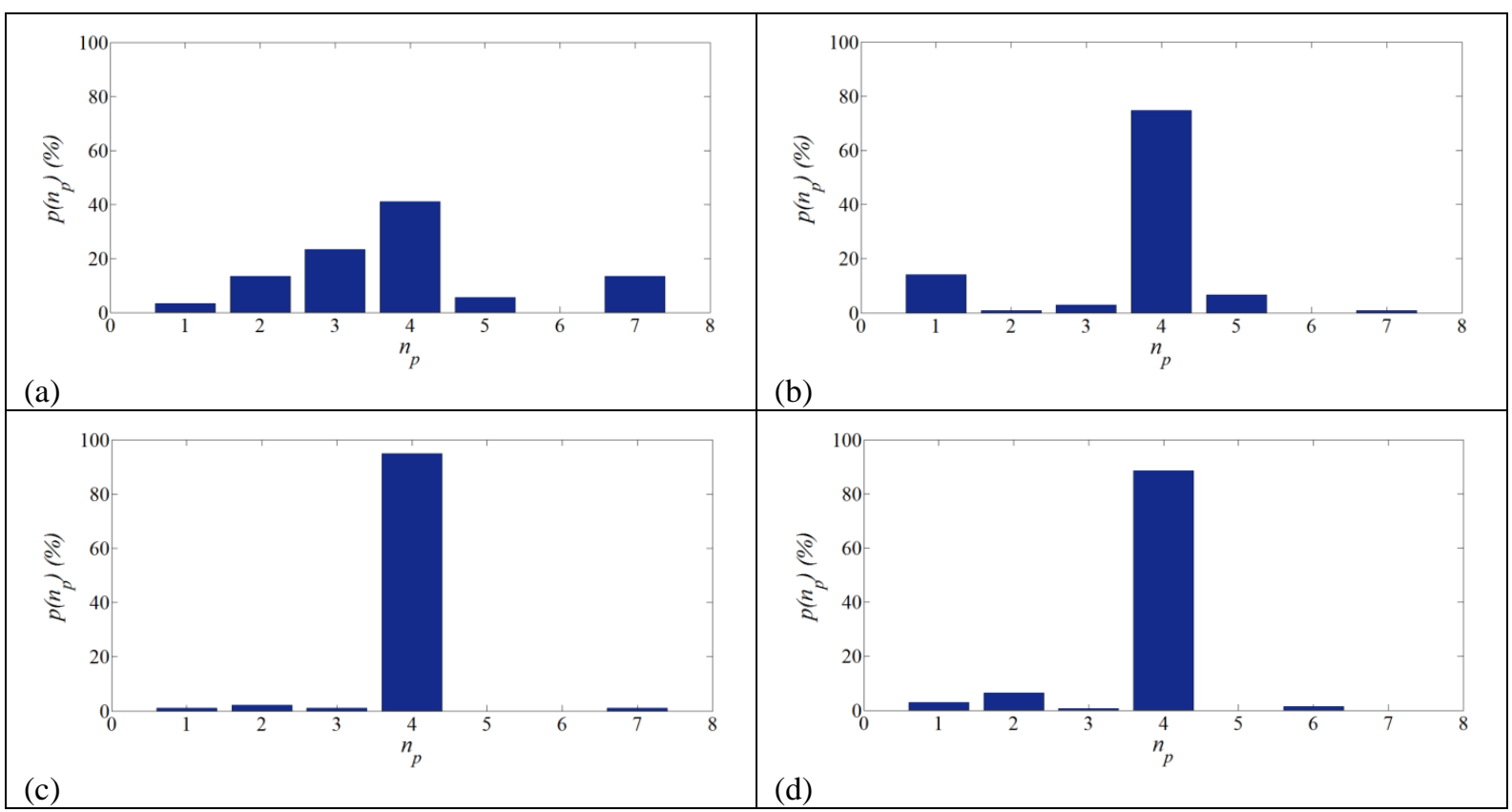

Figure 11. Configuration C8_4. Histograms of the identified damaged storey for the fourth storey of the 8-story building: (a) accelerogram A1, (b) accelerogram A5, (c) accelerogram A6, (d) accelerogram A7.

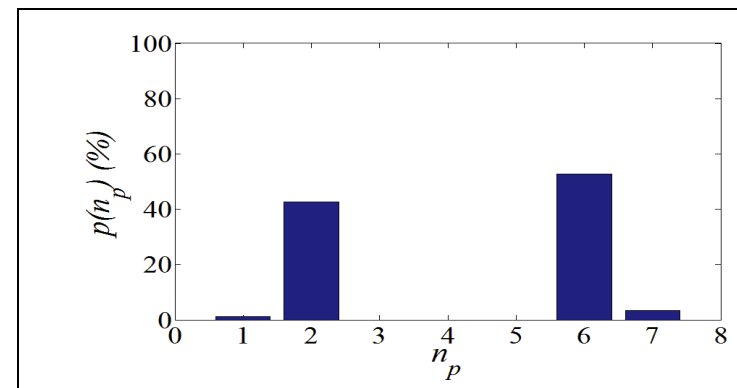

(a)

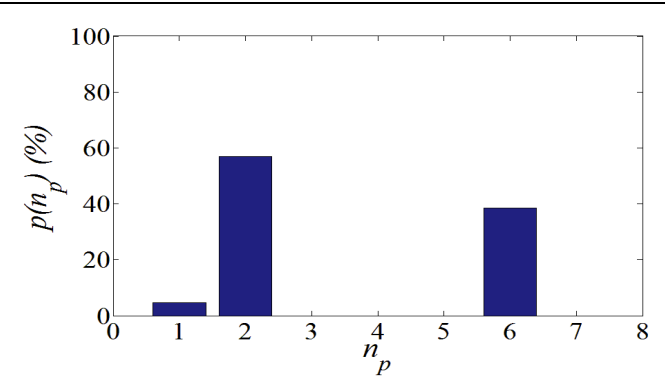

(b) 


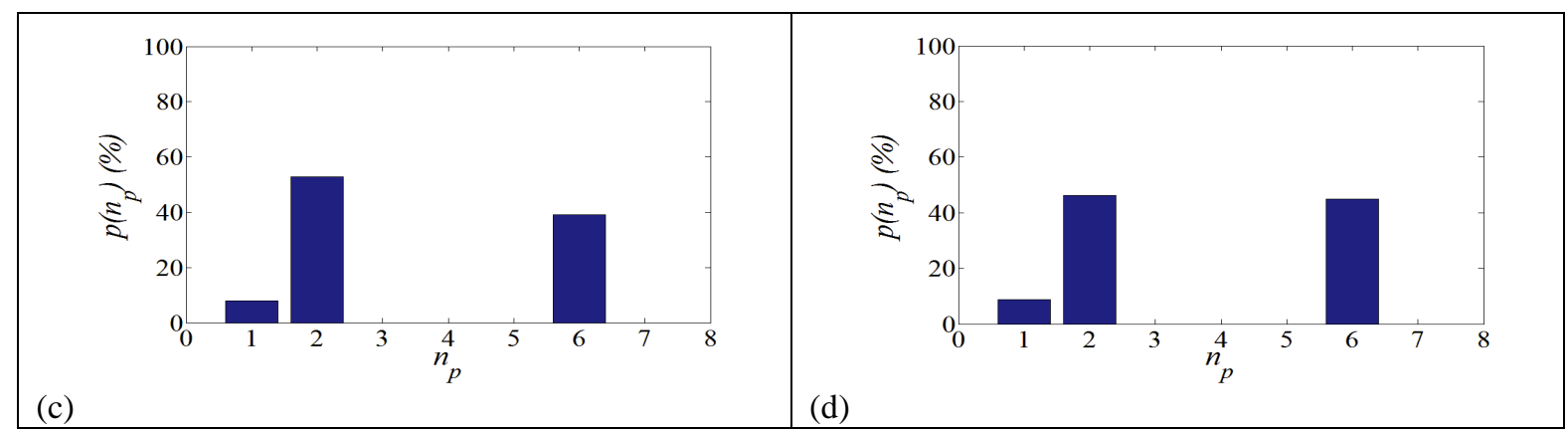

Figure 12. Configuration C8_2_6. Histograms of the identified damaged storey for the second and sixth storeys of the 8-story building: (a) accelerogram A1, (b) accelerogram A5, (c) accelerogram A6, (d) accelerogram A7.

The results of a multiple damage scenario, namely, scenario C8_2_6, are reported in Figure 12; the damages are concentrated in the $2^{\text {nd }}$ and $6^{\text {th }}$ storeys. The damaged locations for the events with lower intensity are also correctly located.

\section{EXPERIMENTAL EXAMPLES}

\subsection{The $7^{\text {th }}$ story shear wall building at UCSD}

\subsubsection{Description of the specimen}

To test and experimentally verify the Interpolation Evolution Method, the algorithm has been applied to a fullscale seven-story reinforced concrete building section tested at University of California-San Diego (UCSD), through the George E. Brown Jr. Network for Earthquake Engineering Simulation (NEES) program [53]-[56].

The test structure, which represents a slice of a full-scale reinforced concrete shear wall building, is 20 metres in height and 275 tons in weight, consists of a main shear wall (web wall), a back wall perpendicular to the main wall (flange wall) for transversal stability, a concrete slab at each floor level, an auxiliary post-tensioned column to provide torsional stability, and four gravity columns to transfer the weight of the slabs to the shake table. Figure 13 shows the test building on the shake table [53].

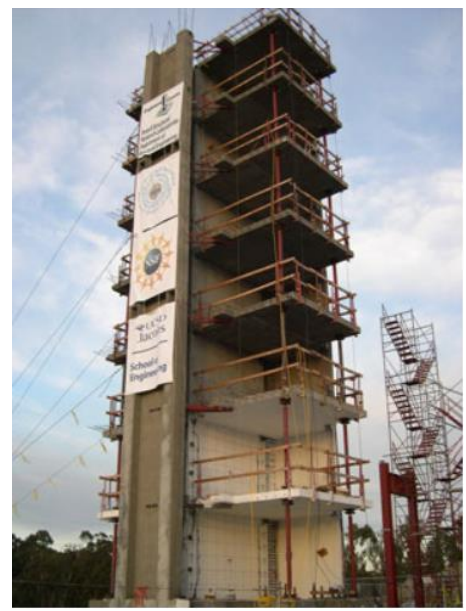

Figure 13. Test structure [53].

The UCSD-NEES shake table is located at the Englekirk Structural Engineering Center, $15 \mathrm{~km}$ east of the main campus of the University of California-San Diego (UCSD). The shake-table tests were designed in order to damage the building progressively through several historical seismic motions reproduced on the shake-table.

The building was subjected to four historical earthquakes of increasing intensity recorded in southern California. Before and between the seismic shake-table tests, the building was subjected to long-duration ( $8 \mathrm{~min})$ ambient vibration tests and to long-duration $(3 \mathrm{~min}$ ) low-amplitude white-noise (WN) excitation tests.

As described in Panagiotou et al. [54], the lowest-intensity input motion EQ1 consisted of the longitudinal component from the Van Nuys (VNUY) station recorded during the 1971 San Fernando earthquake $\left(\mathrm{M}_{\mathrm{W}}=6.6\right)$. The two medium-intensity input motions EQ2 and EQ3 were taken as the transverse components recorded at the VNUY station during the 1971 San Fernando earthquake $\left(\mathrm{M}_{\mathrm{W}}=6.6\right)$ and the longitudinal component from the 
Woodland Hills Oxnard Boulevard (WHOX) station recorded during the 1994 Northridge earthquake $\left(\mathrm{M}_{\mathrm{w}}=6.7\right)$, respectively. The large-intensity input motion EQ4 corresponded to the Sylmar Olive View Med $360^{\circ}$ component recorded during the 1994 Northridge earthquake $\left(\mathrm{M}_{\mathrm{W}}=6.7\right)$. Figure 14 shows the different input motions.
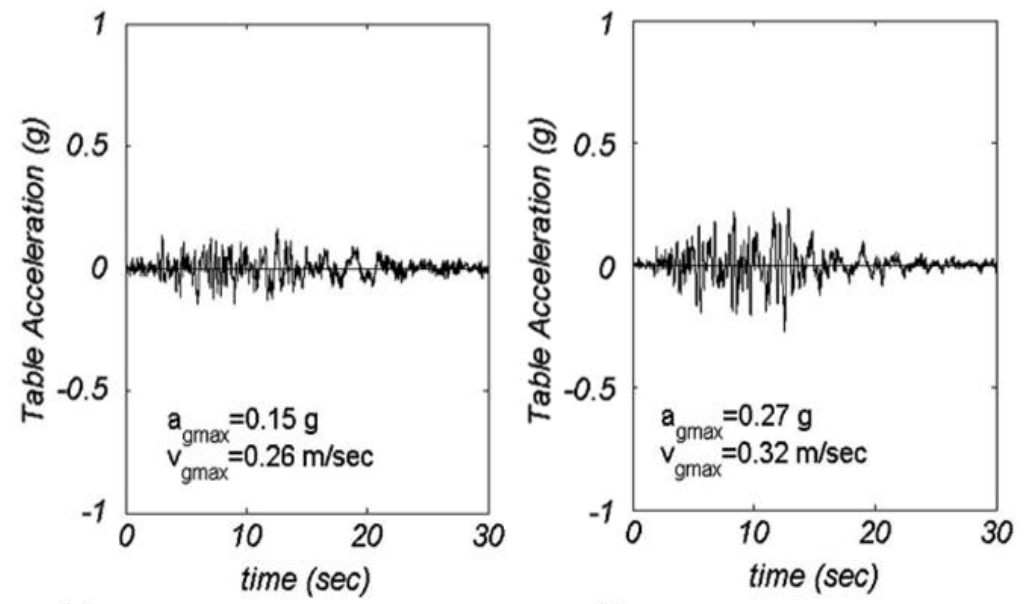

(a)

(b)
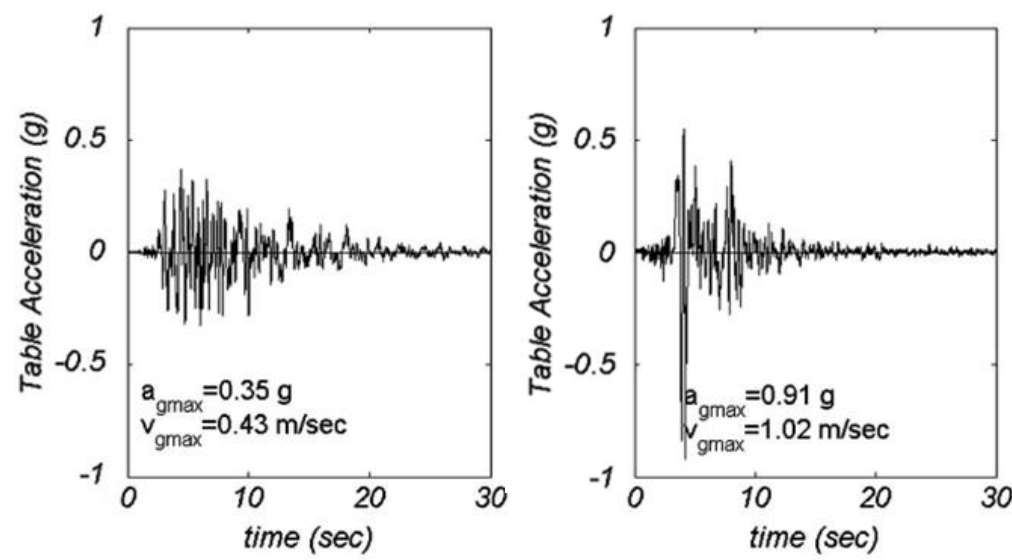

(c)

(d)

Figure 14. Acceleration time histories: (a) EQ1, (b) EQ2, (c) EQ3, (d) EQ4 [54].

The test structure was instrumented with a dense array of sensors in order to measure its dynamic response. The test structure included accelerometers, strain gauges, potentiometers, and linear variable displacement transducers (LVDTs); data was sampled simultaneously using a nine-node distributed data acquisition system. These sensors were sampled at $240 \mathrm{~Hz}$.

In this work, data from 8 longitudinal acceleration channels (located on the web wall at each floor level) were used to apply the proposed damage localization procedure.

\subsubsection{Damage scenario}

As described in Panagiotou et al. [54] and Moaveni et al. [55], after the shaking table tests EQ1-EQ4, the most damaged storeys were the first and the second storeys. Figure 15 shows the structural damage at the bottom of the structure after test EQ4.

In particular, as depicted in Figure 15, flexural cracks occurred at the base of the web wall (this type of damage confirms the considerations made from the results of the dynamic characterization of the model). As described in Moaveni et al. [55], a combination of flexure (horizontal) and flexure-shear (inclined) cracks at the first story of the web wall occurred during seismic test EQ4, around the time of the maximum base rotation of the web wall. Moreover, during seismic test EQ4, a lap-splice failure (i.e., debonding between the longitudinal steel reinforcement bars and the surrounding concrete) occurred in the web wall at the bottom of the second story on the west side. This lap-splice failure was manifested by a large split crack extending one-third of the height of the second level. In addition to the splitting of the concrete in this region, residual crack widths of approximately 1.3 $\mathrm{mm}$ were observed [54]. Figure 15(c) shows the split vertical crack that developed as a result of the lap-splice failure at the west end of the second story. 


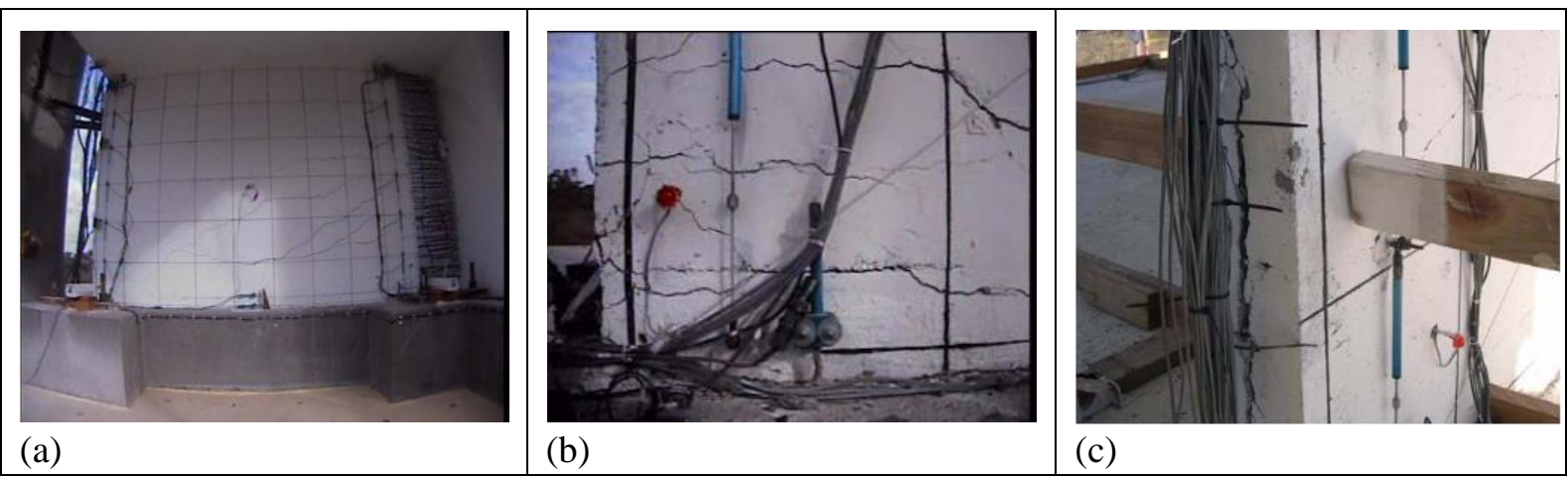

Figure 15. (a) Extent of flexure-shear cracking in the first story (plastic-hinge region) of the web wall and (b) at the bottom corner of the first story of the web wall during EQ4; (c) splitting crack due to lap-splice failure at the bottom of the second story of the web wall on the west side after EQ4 [54].

\subsubsection{Discussion of results}

In this section, the main results obtained from the considered benchmark are presented.

The IM has been applied using the data recorded on the undamaged structure during the ambient vibration tests, with a PGA equal to $0.03 \mathrm{~g}$, and data recorded on the damaged structure under events EQ1 to EQ4. The IM is able to detect the correct location of damage in all cases, while some false alarms are found by applying the CEM (Figure 16). However, the IM cannot be applied using only responses recorded during a single seismic event. The combined IEM is able to detect the correct location of damage in all cases based on the responses recorded during one event, as shown in Figure 17.

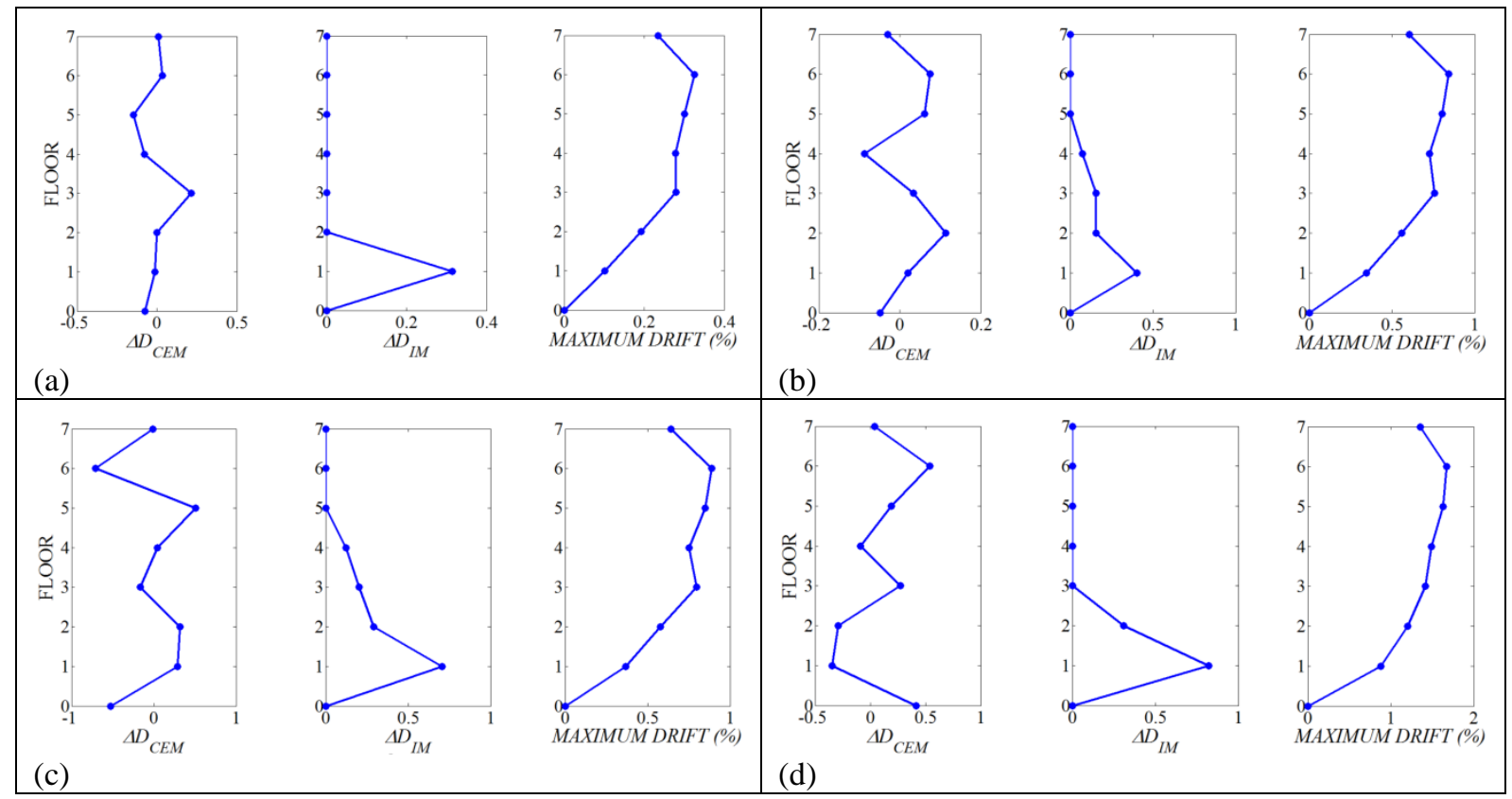

Figure $16.7^{\text {th }}$ story shear wall building at UCSD. Variation in the curvature difference among storeys, and variation in interpolation error and inter-story drift: (a) EQ1, (b) EQ2, (c) EQ3, (d) EQ4.

Analysing the experimental results, the Interpolation Method is able to highlight the position of the structural damage, while the maximum inter-story drift and related curvature variation could be used to detect just nonstructural damages (those that occurred when the maximum inter-story drift exceeded $0.5 \%$ in terms of both the flexural and shear behaviour).

The application of the combined IEM has been carried out by tracking the storey where the maximum variation in the interpolation error occurs. . The histograms of probability are used to detect the damage for each storey of the experimental monitored structure for the different excitations and are shown in Figure 17. In all cases, the correct location of damage is found. Damage is found between storeys 2 and 3 instead of storeys 1 and 2 only for the case of EQ3storeys. 


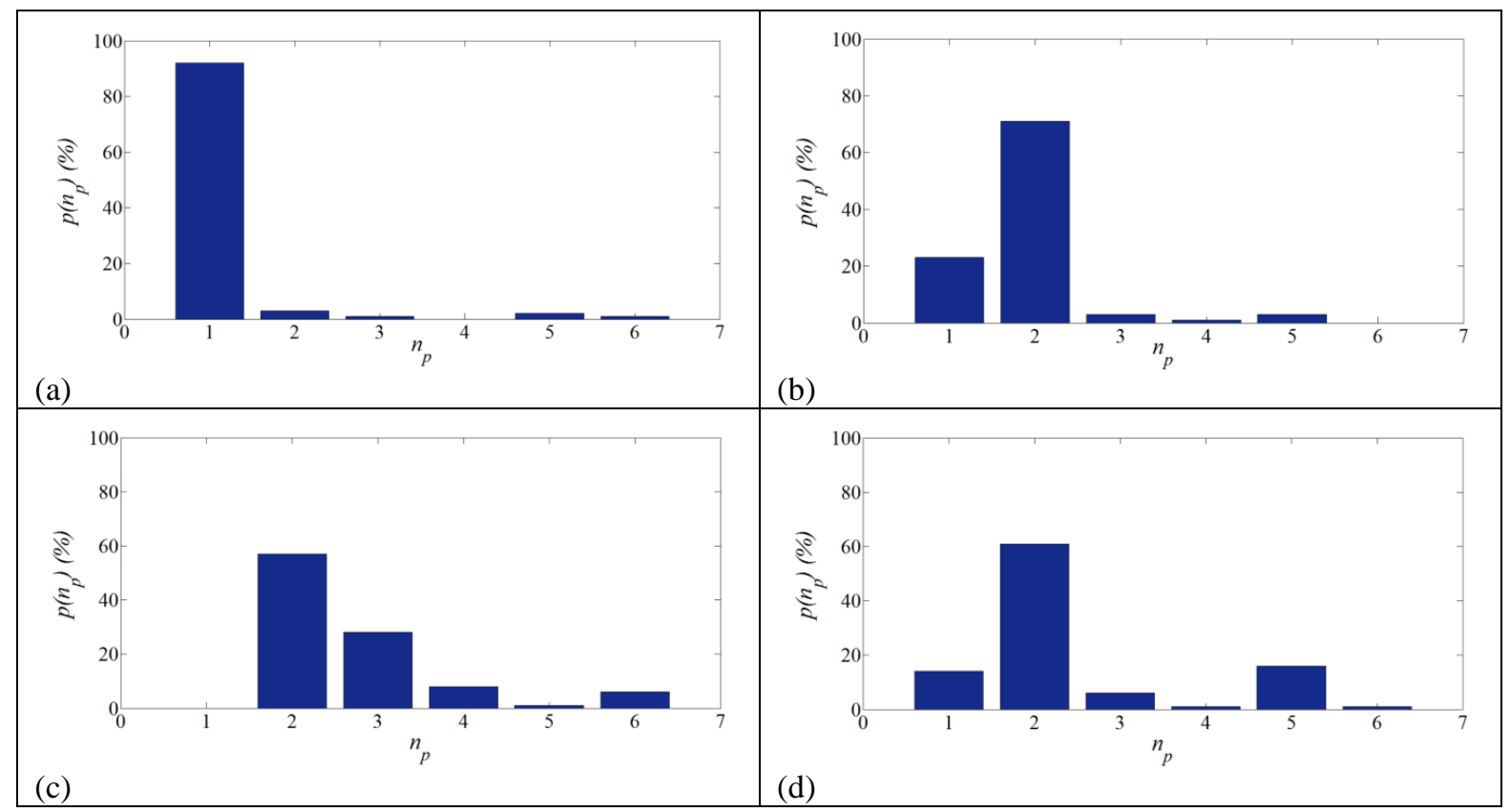

Figure $17.7^{\text {th }}$ story shear wall building at UCSD. Histograms of the identified damaged storey: (a) EQ1, (b) EQ2, (c) EQ3, (d) EQ4.

\subsection{POP model}

\subsubsection{Description of the specimen}

The second example used to validate the proposed Interpolation Evolution Method is a $1 / 4$ reinforced concrete scaled structure designed by considering vertical loads only and tested at the seismic laboratory of the University of Basilicata (Italy) within the POP Project [57]. The structure was tested by performing several mono-axial shaking table tests (Figure 18) under two different boundary conditions: with a fixed base (during Phase 1) and with a base isolation system (during Phase 2).

During the experimental campaign, the POP model was excited by natural and artificial mono-directional earthquakes. The natural seismic input used in both projects was the Colfiorito record of the 1997 Umbria-Marche earthquake in Italy, while the artificial seismic input considered was derived from the response spectrum provided by Eurocode 8 for soil type B. Both acceleration time histories were scaled in time for consistency with the scale factor of the model. In the POP project, for the tests in the fixed base configuration, the effective peak acceleration of the table was progressively increased from $0.05 \mathrm{~g}$ up to $0.35 \mathrm{~g}$ (considering different spectral shapes). The displacement time-history related to each story of the model has been recorded by means of Temposonic digital transducers fixed to an external steel framed structure that is used as reference. Furthermore, a system of horizontal servo-accelerometers was deployed on the structure to acquire the acceleration time histories at each floor [58].

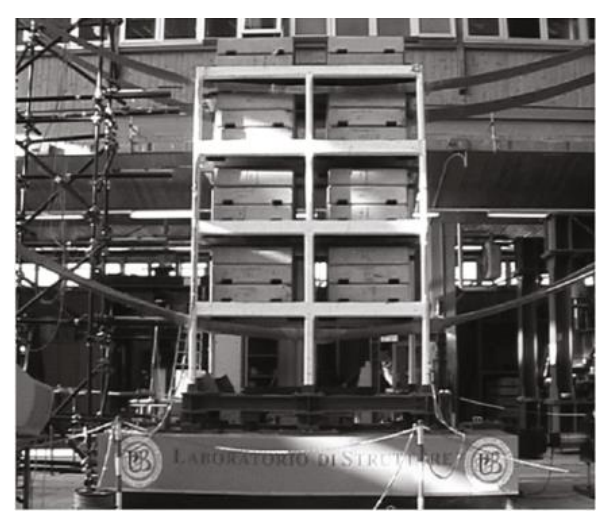

Figure 18. POP model [58].

\subsubsection{Discussion of results}


In this section, the main results obtained by applying the three methods for damage localization (IM, CEM, and IEM) to the POP model are reported. The IM is applied using data recorded on the undamaged structure during a test with a PGA equal to $0.1 \mathrm{~g}$ and data recorded on the damaged structure during a shaking table test with a PGA between $0.15 \mathrm{~g}$ and $0.30 \mathrm{~g}$.

Figure 19 shows the results retrieved from the CEM and IM for different excitations: the absolute value of the variation in the curvature difference $\left(\Delta \mathrm{D}_{\mathrm{CEM}}\right)$ and the variation in the interpolation error $\left(\Delta \mathrm{D}_{\mathrm{IM}}\right)$. In addition, the values of the inter-story drift have been computed for all the stories using the responses recorded by the displacement transducers installed on the model during the experimental campaign.

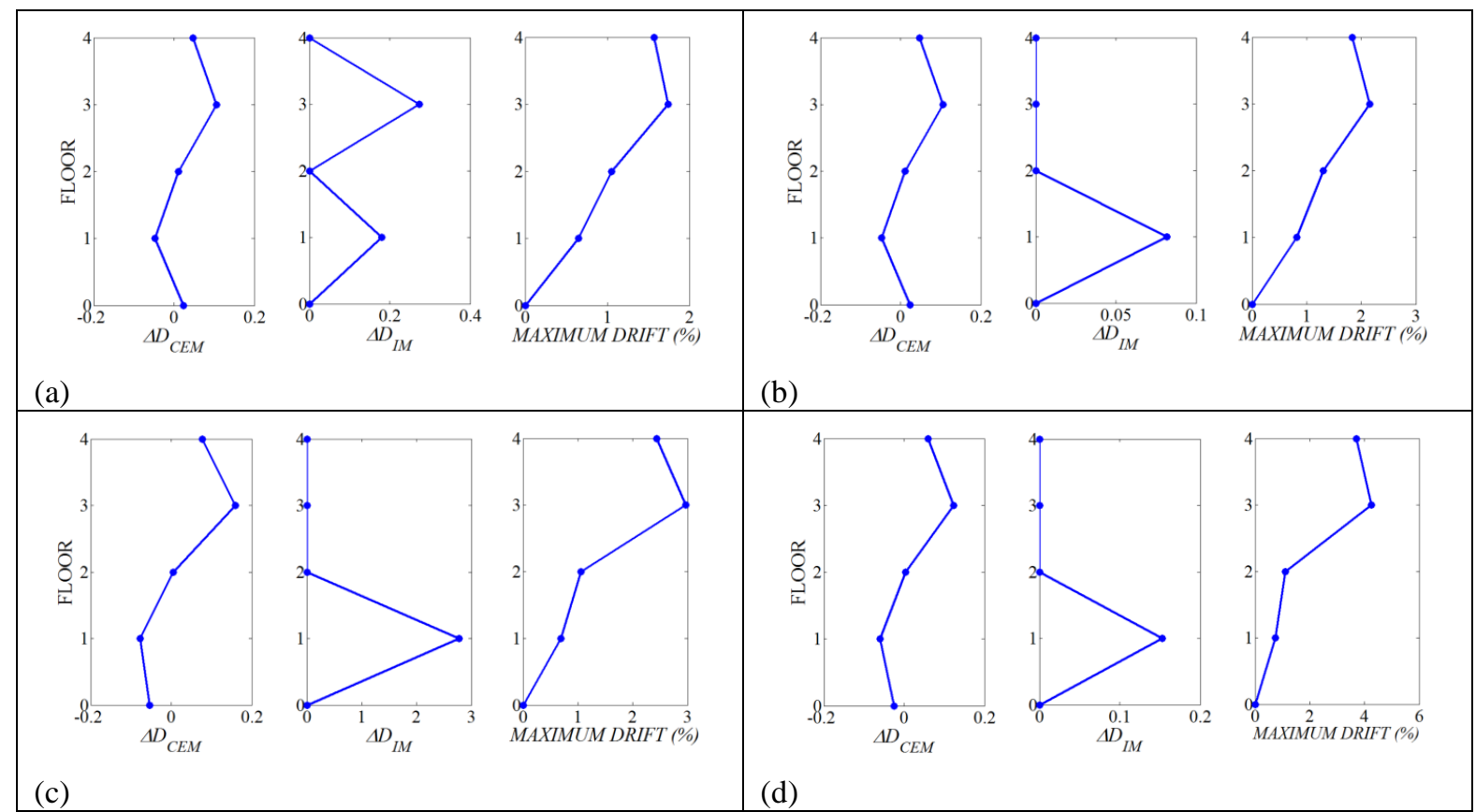

Figure 19. POP model. Variation in curvature difference among storeys, and variation in interpolation error and inter-story drift for different values of PGA: (a) $0.15 \mathrm{~g}$, (b) $0.20 \mathrm{~g}$, (c) $0.25 \mathrm{~g}$, (d) $0.30 \mathrm{~g}$.

It can be observed that the results of the CEM are in agreement with the patterns shown by the maximum interstory drift, which reached its maximum value at the $3^{\text {rd }}$ storey for all cases. The IM in these cases does not detect the correct location of damage.

The histograms are reported in Figure 20 and show that the third storey is the most damaged location; this result is consistent with the patterns retrieved from the inter-story drift data.

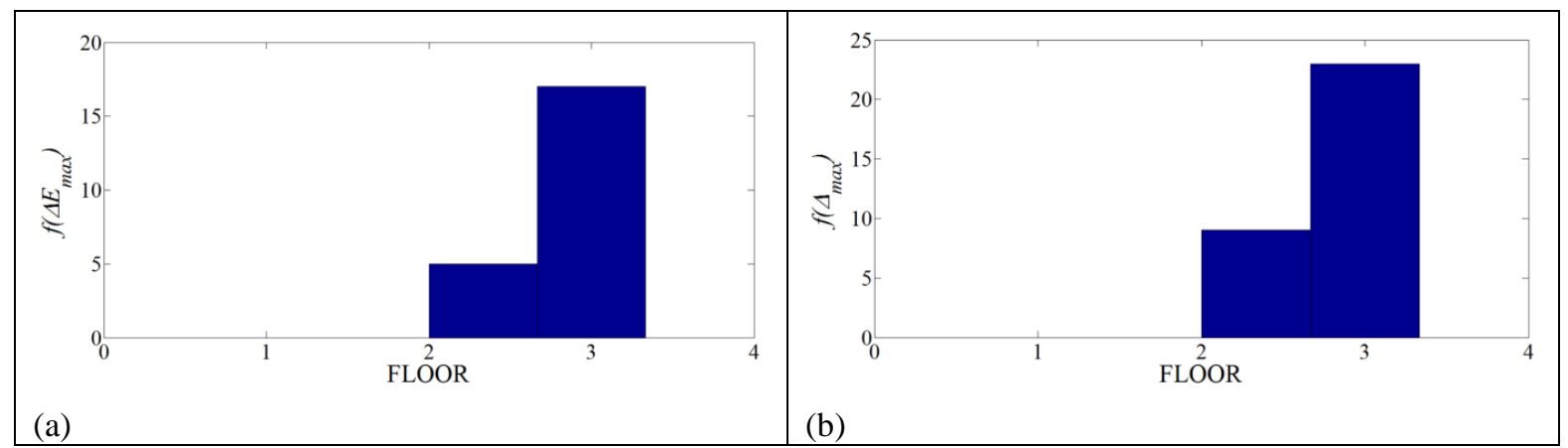




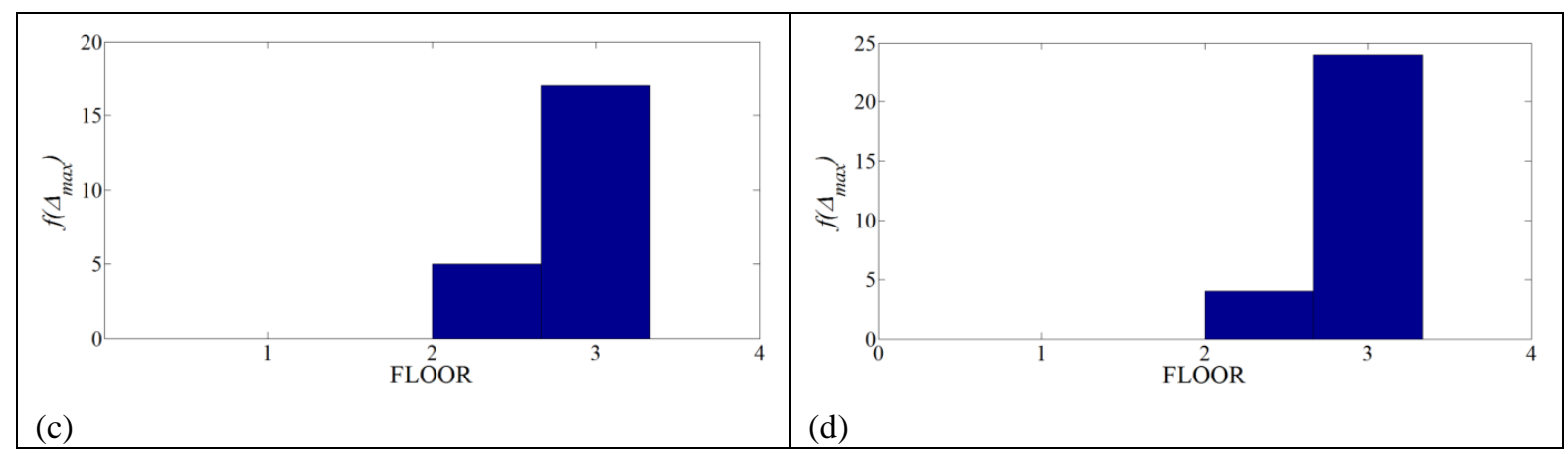

Figure 20. POP model. Histograms of the identified damaged storey: (a) $0.15 \mathrm{~g}$, (b) $0.20 \mathrm{~g}$, (c) $0.25 \mathrm{~g}$, (d) $0.30 \mathrm{~g}$.

It is noted that, as shown by the previous figures, in all cases, the proposed method gives some false alarms. This occurs for all methods of damage identification when applied to real data. The number of false alarms could have been reduced by defining a threshold for the damage feature, but this would have increased the number of missing alarms. Without a cost/benefit analyses, based on the consequences connected to false or missing alarms, which was not the aim of this paper, any threshold is questionable. This paper shows that when damage is present, the proposed method is able to detect and localize it. The definition of a threshold as a trade-off between the number of false and missing alarms will be the subject of further investigations.

\section{CONCLUSIONS}

In this work, the Interpolation Evolution Method (IEM) has been proposed for damage localization based on the responses recorded on a structure during an earthquake. The method is the combination of two existing methods: the Curvature Evolution Method (CEM) and the Interpolation Method (IM). The CEM, derived from the properties of the S-Transform and of the band-variable filter, allows retrieval of the variations in each mode of vibration within both the linear and the nonlinear fields from recorded responses. This enables the damage evolution to be determined for a monitored structure (during an earthquake) through the changes in the difference in curvature between adjacent storeys with time. The IM is able to detect localized losses of smoothness in a modal, or operational, shape through interpolation with a smooth cubic spline function with respect to a reference condition preceding the earthquake. This procedure allows the detection of localized variations in curvature without estimating the curvature, overcoming problems related to the differentiation in the case of noisy signals. Combining the two methods (IEM) enables exploitation of the advantages of the two methods: the possibility to follow the evolution of the damage feature throughout the entire seismic event (CEM) and to avoid the curvature estimation (IM). Specifically, the proposed IEM detects the location of damage at each time, thus providing a large population of values of the damage feature, allowing retrieval of its statistical distribution during the earthquake. The location of damage is assumed as the location corresponding to the maximum frequency of detection.

In this paper, the combined IEM has been applied and validated to both nonlinear numerical models and to the responses retrieved from two experimental cases of reinforced concrete multi-storey frames, one tested on the shaking table of the UCSD-NEES and the other on the shaking table of the University of Basilicata. The results show that for the considered experimental cases, the combined method is able to successfully detect the correct location of damage, while the application of the IM and/or the CEM alone fails to correctly locate damage in some cases.

\section{ACKNOWLEDGEMENTS}

The seismic inputs were provided by the Italian Accelerometric Archive (ITACA). The use of the data recorded on the $7^{\text {th }}$ storey UCSD building is gratefully acknowledged. This study was partially funded by the Italian Civil Protection Department within project DPC-RELUIS 2017-2018.

\section{REFERENCES}

[1] Doebling SW, Farrar CH, Prime MB, Shevitz DW. Damage identification and health monitoring of structural and mechanical systems from changes in their vibration characteristics: a literature review. Los Alamos National Laboratory Report, New Mexico. 1996. 
[2] Doebling SW, Farrar CH, Prime MB. A summary review of vibration-based damage identification methods. The Shock and Vibration Digest 1998; 30(2):99-105.

[3] Sohn H, Farrar CR, Hemez FM, Shunk DD, Stinemates DW, Nadler BR. A review of structural health monitoring literature: 1996-2001. Rep. No. LA-13976-MS, Los Alamos National Laboratory, Los Alamos, N.M., 2003.

[4] Sanghyun C, Sooyong P, Sungwon Y, Norris S. Nondestructive damage identification in plate structures using changes in modal compliance. NDT\&E International 2005; 38:529-540.

[5] Ponzo FC, Ditommaso R, Auletta G, Mossucca A. A Fast Method for Structural Health Monitoring of Italian Strategic Reinforced Concrete Buildings. Bulletin of Earthquake Engineering 2010; 8(6):1421-1434, DOI: 10.1007/s10518-010-9194-6.

[6] Omrani R, Hudson RE, Taciroglu E. Story-by-story estimation of the stiffness parameters of laterallytorsionally coupled buildings using forced or ambient vibration data: I. Formulation and verification. Earthquake Engng Struct Dyn 2011; DOI: 10.1002/eqe.1192.

[7] Omrani R, Hudson RE, Taciroglu E. Story-by-story estimation of the stiffness parameters of laterallytorsionally coupled buildings using forced or ambient vibration data: II. Formulation and verification. Earthquake Engng Struct Dyn 2011; DOI: 10.1002/eqe.1193.

[8] Bisht SS, Singh MP. Detecting sudden changes in stiffness using high-pass filters. Struct. Control Health Monit 2012; 19:319-331, DOI: 10.1002/stc.433.

[9] Dinh HM, Nagayamaz T, Fujinoy Y. Structural parameter identification by use of additional known masses and its experimental application. Struct Control Health Monit 2012; 19:436-450, DOI: 10.1002/stc.444.

[10] Limongelli MP. Damage localization in a glass fiber reinforced composite plate via the surface interpolation method. Journal of Physics: Conference Series, 628, 2015.

[11] Pai PF, Young LG. Damage detection of beams using operational deflection shapes. International journal of Solids and Structures 2001; 38:3161-3192.

[12] Amezquita-Sanchez JP, Adeli H. Signal Processing Techniques for Vibration-Based Health Monitoring of Smart Structures, Archives of Computational Methods in Engineering 2016; 23:1-15.

[13] Fan W, Qiao P. Vibration-based damage identification methods: a review and comparative study. Structural Health Monitoring 2011; 10(1):83-29.

[14] Yan YJ, Cheng L, Wu ZY, Yam LH. Development in vibration-based structural damage detection technique. Mechanical Systems and Signal Processing 2007; 21(5):2198-2211.

[15] Farrar CR, Doebling SW, An overview of modal-based damage identification methods. EUROMECH 365 International Workshop: DAMAS 97, Structural Damage Assessment Using Advanced Signal Processing Procedures, Sheffield, U.K., 1997.

[16] Pandey AK, Biswas M, Samman MM. Damage detection from changes in curvature mode shapes. Journal of Sound and Vibration 1991; 145(2):321-332.

[17] Pandey AK, Biswas M. Damage Detection in Structures Using Changes in Flexibility. Journal of Sound and Vibration 1994; 169(1):3-17.

[18] Y.K. Ho, D.J. Ewins, On the structural damage identification with mode shapes. Proc. of the European COST F3 Conference on Structural Identification and Structural Health Monitoring, Madrid, Spain, 677-686, 2000.

[19] Topole KG, Stubbs N. Non-destructive damage evaluation of a structure from limited modal parameters. Earthquake Engineering and Structural Dynamics 1995; 24:1427-1436.

[20] Kim JT, Stubbs N. Improved damage identification method based on modal information. Journal of Sound and Vibration 2002; 252(2):223-238.

[21] Xia Y, Hao H, Brownjohn JMW, Xia PQ. Damage identification of structures with uncertain frequency and mode shape data. Earthquake Engineering and Structural Dynamics 2002; 31:1053-1066.

[22] Bindi D, Petrovic B, Karapetrou S, Manakou M, Boxberger T, Raptakis D, Pitilakis KD, Parolai S. Seismic response of an 8-story RC-building from ambient vibration analysis, Bulletin of Earthquake Engineering 2015; 13:2095-2120.

[23] Poudel UP, Fu G, Ye J. Wavelet transformation of mode shape difference function for structural damage location identification. Earthquake Engineering and Structural Dynamics 2007; 36:1089-1107.

[24] Limongelli MP. The interpolation damage detection method for frames under seismic excitation. Journal of Sound and Vibration 2011; 330:5474-5489.

[25] Capecchi D, Vestroni F. Monitoring of structural systems by using frequency data. Earthquake Engineering and Structural Dynamics 1999; 28:447-461.

[26] Morassi A. Crack Induced Changes in Eigenparameters of Beam Structures. Journal of Engineering Mechanics 1993; 119.

[27] Cawley P. Adams RD. The location of defects in structures from measurements of natural frequencies. The Journal of Strain Analysis for Engineering Design 1979; 14:49-57. 
[28] Sohn H, Dzwonczyk M, Straser EG, Kiremidjian AS, Law KH, Meng T. An experimental study of temperature effect on modal parameters of the Alamosa Canyon Bridge. Earthquake Engineering \& Structural Dynamics 1999; 28:879-897.

[29] Sohn H. Effects of environmental and operational variability on structural health monitoring, Philosophical Transactions of the Royal Society 2007; 365:539-560.

[30] Peeters B, De Roeck G. One year monitoring of the Z24 bridge: environmental influences versus damage effects. In: Proceedings of the IMAC-XVIII San Antonio, TX, 2000; pp. 1570-1576.

[31] Kullaa J. Structural health monitoring under variable environmental or operational conditions. In: Proceedings of the Second European Workshop on Structural Health Monitoring, Germany, 2004; pp. 1262 1269.

[32] Yan AM, Kerschen G, De Boe P, Golinval JC. Structural damage diagnosis under varying environmental conditions — Part I: A linear analysis. Mechanical Systems and Signal Processing 2005; 19:847-864.

[33] Yan AM, Golinval JC. Null subspace-based damage detection of structures using vibration measurements. Mechanical Systems and Signal Processing 2006; 20:611-626

[34] Ditommaso R, Ponzo FC, Auletta G. Damage detection on framed structures: modal curvature evaluation using Stockwell Transform under seismic excitation. Earthquake Engineering and Engineering Vibration $2015 ; \mathbf{1 4}: 265-274$

[35] Limongelli MP. Structural damage localization using the modal interpolation method. Proc. 8EWSHM. July 2016. Bilbao, Spain.

[36] Sampaio RPC, Maia NMM, Silva JMM. Damage detection using the frequency response function curvature method. Journal of Sound and Vibration 1999; 226(5):1029-1042.

[37] Ratcliffe CP. Damage Detection Using A Modified Laplacian Operator On Mode Shape Data. Journal of Sound and Vibration 1997; 204(3):505-517.

[38] Limongelli MP. Frequency response function interpolation for damage detection under changing environment. MSSP doi:10.1016/j.ymssp.2010.03.004, 2010.

[39] Limongelli MP. Optimal location of sensors for reconstruction of seismic responses through spline function interpolation. Earthquake Engineering and Structural Dynamics 2003; 32:1055-1074.

[40] Fan W, Qiao P. Vibration-based Damage Identification Methods: A Review and Comparative Study. Structural Health Monitoring 2011; 10(1):83-29.

[41] Limongelli MP. Seismic health monitoring of an instrumented multistory building using the interpolation method. Earthquake Engineering and Structural Dynamics 2014.

[42] Ditommaso R, Mucciarelli M, Ponzo FC. Analysis of non-stationary structural systems by using a bandvariable filter. Bulletin of Earthquake Engineering 2012; 10(3):895-911; DOI: 10.1007/s10518-012-9338-y.

[43] Stockwell RG, Mansinha L, Lowe RP. Localization of the complex spectrum: the S transform. IEEE Trans Signal Process 1996; 44:998-1001.

[44] Gabor D. Theory of communications. J Inst Elect Eng 1946; 93:429-457.

[45] Ditommaso R, Ponzo FC, Auletta G, Iacovino C. Testing a new procedure for damage detection on framed structures subjected to strong motion earthquakes. Second European conference on Earthquake Engineering and Seismology, Istanbul Aug. 25-29, 2014.

[46] Cao M, Xu W, Ostachowicz W, Su Z. Damage identification for beams in noisy conditions based on Teager energy operator-wavelet transform modal curvature. Journal of Sound and Vibration 2014; 333:1543-1553.

[47] SAP2000. Computers \& Structures. https://www.csiamerica.com/products/sap2000

[48] Laxalde D., Thouverez F. Complex non-linear modal analysis for mechanical systems: Application to turbomachinery bladings with friction interfaces.

[49] Ditommaso R, Ponzo FC. Automatic evaluation of the fundamental frequency variations and related damping factor of reinforced concrete framed structures using the Short Time Impulse Response Function (STIRF). Engineering Structures 2015; 82:104-112.

[50] Limongelli MP, Domaneschi M, Martinelli L. Vibration-based damage severity estimation basing on a nonmodel damage feature. IALCCE 2016. Delft, The Netherlands.

[51] Nuove norme tecniche per le costruzioni. D.M. Infrastrutture 14 Gennaio 2008.

[52] Calvi GM. Scelte e criteri per il consolidamento sismico. Progettazione Sismica 2013; Vol.4, n.1.

[53] NEES Network for Earthquake Engineering Simulation Project (http://nees.ucsd.edu/7story.html).

[54] Panagiotou M, Restrepo J, Conte J. Shake-Table Test of a Full-Scale 7-Story Building Slice. Phase I: Rectangular Wall. Journal of Structural Engineering 2011; 10.1061/(ASCE)ST.1943-541X.0000332, 691704.

[55] Moaveni B, He X, Conte JP, Restrepo JI. Damage Identification Study of a Seven-Story Full-scale Building Slice Tested on the UCSD-NEES Shake Table. Structural Safety 2010; 32(5):347-356.

[56] Moaveni B, He X, Conte JP, Restrepo JI Panagiotou M. System Identification Study of a Seven-Story Fullscale Building Slice Tested on the UCSD-NEES Shake Table. Journal of Structural Engineering 2011; ASCE, 137(6). 
[57] Dolce M, Cardone D, Di Cesare A, Moroni C, Nicoletti M, Ponzo FC and Nigro D. Dynamic Tests on a 1:4 Scaled R/C Existing Building: Comparison of Several Isolation Systems, 9th Assisi, Kobe 2005.

[58] Ponzo FC, Ditommaso R, Auletta G, Mossucca A. A fast method for structural health monitoring of Italian strategic reinforced concrete buildings. Bull Earthquake Eng 2010; 8:1421-1434. 